\title{
Arbor
}

\section{Los servicios de inteligencia en la historiografía española}

\author{
Juan R. Goberna Falque
}

Arbor CLXXX, 709 (Enero 2005), 25-74 pp.

El objetivo prioritario de este artículo es la presentación del primer balance completo de la historiografía española sobre inteligencia, espionaje $y$ temas afines. Como paso previo, el autor ha realizado una base de datos que cuenta en estos momentos con algo más de 1000 entradas, una cifra nada desdeñable que por sí sola demuestra que la bibliografía española sobre estas materias no es tan escasa como los principales especialistas en el tema suelen afirmar. Un porcentaje muy elevado de las referencias corresponden a trabajos publicados en los últimos doce años, periodo en el que estos estudios han experimentado una progresión exponencial. Sin embargo, el carácter poco sistemático y disperso de la producción está lastrando gravemente su progreso, lo cual redunda en una imagen de cierta pobreza teórica y metodológica. A nuestro juicio, si de verdad queremos avanzar en la promoción de la "cultura de la inteligencia», es imprescindible que se acometa una serie de cambios en la legislación que permitan, entre otras mejoras, el establecimiento de nuevos mecanismos de desclasificación documental. Poco importa quienes sean los encargados de llevar a cabo la historia de los servicios de inteligencia en España. Lo único que nunca debemos de perder de vista es el carácter riguroso de la empresa.

Proponemos en este artículo una primera aproximación a la producción historiográfica española referida específicamente a la historia del espionaje y a todos aquellos temas vinculados tradicionalmente a los servi- 
cios de inteligencia ${ }^{1}$. Nuestro punto de partida ha sido la creación de una base de datos bibliográfica a partir de las informaciones recogidas en una amplia serie de compilaciones y repertorios especializados ${ }^{2}$. Muy fructífera, a su vez, ha resultado la consulta de la Recopilación digital de Publicaciones Periódicas de Defensa, disponible recientemente en DVD, que nos ha facilitado el vaciado de las revistas militares españolas más importantes ${ }^{3}$. La ayuda tecnológica en el rastreo bibliográfico compensa, en parte, la ardua tarea de elaboración de dicha base de datos, dado que el principal problema al que nos hemos enfrentado es la total inexistencia de precedentes al respecto ${ }^{4}$. Un ejemplo significativo: de las 10369 reseñas bibliográficas incluidas en una de las principales summae especializadas, Intelligence, Espionage and Related Topics. An Annotated Bibliography of Serial Journal and Magazine Scholarship. 1844-1998, únicamente 72 están directamente relacionadas con España y se refieren, además, a artículos publicados fundamentalmente por autores anglosajones.

1 El presente trabajo se inscribe en el marco del proyecto de investigación «Espionaje y relaciones internacionales: los servicios de información aliados en España durante la Primera Guerra Mundial» (BHA2002-01143) en el que participa el autor. Este proyecto, dirigido por F. GARCía SANZ, se desarrolla actualmente en el Departamento de Historia Contemporánea del Instituto de Historia del CSIC.

2 Cabe destacar, por la gran cantidad de títulos que hemos ido encontrando, las siguientes bases de datos: «Bibliografía de la Literatura Española desde 1980»; «Biblio grafía General Española»; «Bibliografía Nacional Española»; «Francis»; «Historical Abs tracts»; "ISOC»; "MLA: Modern Language Association»; "PCI Full Text»; "Teseo» o «Wilson Humanities Index». Los catálogos de algunas bibliotecas nos han sido de gran utilidad, especialmente el CIRBIC (Red de Bibliotecas del CSIC); Rebiun (catálogo colectivo de la Red de Bibliotecas Universitarias Españolas); la Biblioteca Nacional de Es paña, la Bibliothèque Nationale de France, la British Library, el Instituto de Historia y Cultura Militar, Iberlibro, etc.

${ }^{3}$ V. gr.: Revista General de Marina, Ejército, Revista de Historia Militar, Revista de Historia Naval, Revista de Aeronáutica y Astronáutica, Aeroplano o la colección de Monografias del Ceseden.

4 El único balance relativamente similar del que tengamos conocimiento es el que ha llevado a cabo recientemente M. ESPADAS BuRgos en una ponencia titulada «Los Servicios de Información en la transición al mundo contemporáneo. El estado de la cuestión», en el marco de un seminario sobre «Los servicios de información modernos y contemporáneos», celebrado en el Instituto de Historia y Cultura Militar en noviembre de 2004. Las Actas de dicho seminario serán publicadas próximamente en la Revista de Historia Militar.

5 J. D. CALDER (comp.), Intelligence, Espionage and Related Topics. An Annotated Bibliography of Serial Journal and Magazine Scholarship. 1844-1998, Westport [Connecticut]; Londres, Greenwood Press, 1999. 
El protocolo de búsqueda ha sido siempre el mismo. Se ha tratado de localizar e identificar todas aquellas publicaciones (libros, monografías, artículos especializados, etc.) que tuviesen relación con nuestro tema de investigación: la historia de los servicios de inteligencia españoles. Así, el listado de palabras clave (keywords) al que hemos recurrido en la gran mayoría de las ocasiones incluía voces como «espía», «espionaje», «inteligencia", "servicio secreto", "servicio de inteligencia», etc., tanto en singular como en plural, casi siempre en castellano, y con la combinación de varios criterios (búsqueda booleana). Debido a la gran generalidad del tema de investigación, hemos decidido sistematizar las informaciones recogidas en la base de datos y llevar a cabo una selección previa. En este sentido, hemos procurado recopilar con la mayor exhaustividad que nos ha sido posible todos aquellos trabajos publicados por autores españoles sobre la historia de la inteligencia en nuestro país, del mismo modo que hemos optado por dejar de lado aquellos otros que hemos considerado menos relevantes. Así, por ejemplo, el interés de la historiografía española por las actividades de espionaje desarrolladas en otros países y que hayan tenido escasa o nula incidencia sobre el desarrollo de la política española ha sido realmente muy limitado ${ }^{6}$. Por lo que se refiere a la historiografía de otros países en los que se hace referencia a sucesos acaecidos en España o protagonizados por españoles, hemos preferido recoger únicamente las obras más significativas, sobre todo si éstas cubren una laguna importante de la historiografía española sobre un periodo concreto. $\mathrm{Y}$ del mismo modo, tampoco aparecen reflejadas las traducciones al español de obras sobre inteligencia y espionaje publicadas originariamente en el extranjero.

Nuestra base de datos nos ha permitido elaborar una guía bibliográfica en función de un criterio principal, de orden cronológico, que explica su subdivisión en tres grandes secciones: «Historia moderna de España», «Historia Contemporánea de España» e «Historia actual». La organización interna de cada uno de estos epígrafes, a su vez, responde al sometimiento a una ordenación temática. Hemos seguido criterios relativamente flexibles en lo que al orden en que los distintos trabajos están citados se refiere. Hemos preferido privilegiar las monografías, los libros o las tesis doctorales sobre los artículos de investigación, las contribuciones a congresos o los trabajos de divulgación; en algunos casos, aparecen

${ }^{6}$ Estas referencias, pese a haber sido incluidas en nuestra base de datos, no van a ser presentadas en este balance. 
citados primero los trabajos más antiguos y a continuación los más recientes; y a veces incluso hemos optado por referirnos en primer lugar a las obras más relevantes sobre un determinado tema, independientemente de su fecha de publicación.

Los principales especialistas se han lamentado de la gran debilidad de la historiografía española sobre espionaje e inteligencia. Todavía en 1996 Fé lix Luengo Teixidor hacía el siguiente balance de la producción autóctona: «Los servicios de información secreta son, dentro de la historia contemporá nea española, grandes desconocidos. Apenas aparecen mencionados en la bi bliografia y apenas hay referencias ni tan siquiera a su mera existencia, y mucho menos a su desarrollo, a su actividad, a los resultados de su peculiar trabajo, a su eficacia o ineficacia o a su posible influencia en los avatares políticos o militares de nuestro pasado. (...) En realidad, sólo a partir de los años de la transición, tras la muerte de Franco, y en la etapa democrática más reciente hemos empezado a conocer algo sobre ellos, sobre su actividad y su organización, en gran parte gracias a trabajos meramente periodísticos. Aunque tampoco demasiado. De etapas anteriores, de sus primeros orígenes y de su desarrollo y actividades en los regímenes anteriores, hay un vacío casi absoluto» ${ }^{7}$. Sin embargo, actualmente contamos con algo más de 1000 entradas en nuestra base de datos ${ }^{8}$, un número que por sí sólo indica que la producción bibliográfica española sobre servicios de inteligencia no es tan escasa como en un principio pudiera parecer. ¿Cómo podemos explicar esta aparente contradicción entre el análisis realizado hace menos de una déca da por Luengo Teixidor y los datos con los que contamos en la actualidad? Simplemente, a partir de las informaciones extraídas de nuestra propia base de datos, que nos indican que ha sido precisamente en los últimos diez o doce años cuando se ha producido un salto cuantitativo en lo que a la producción de estudios sobre inteligencia se refiere. Sigue siendo cierto que no existe nada que se parezca a una tradición historiográfica propia, pero al menos podemos señalar ya la existencia de dos etapas netamente identificables en el desarrollo cronológico de estos estudios en España:

7 F. LUENGo TEIXIDOR, Espías en la Embajada: los servicios de información secreta republicanos en Francia durante la Guerra Civil, [Bilbao], Servicio Editorial de la Universidad del País Vasco, 1996, 13.

8 Nuestra intención es seguir enriqueciendo progresivamente esta base de datos con las publicaciones que vayan apareciendo a lo largo de los próximos años y, llegado el momento, ponerla a disposición de los investigadores en una futura monografía en la que se expondrán, además, los principales resultados obtenidos por el equipo de investigación que está trabajando en el proyecto anteriormente citado en la nota 1. 
Los servicios de inteligencia en la historiografía española

1. 1940-1990: Esta larguísima etapa corresponde al periodo de nacimiento y dificultoso desarrollo de este ámbito de estudios en la historiografía española. Desde el final de la Guerra Civil, el mercado editorial español está copado por traducciones de libros norteamericanos e ingleses y los únicos trabajos publicados por autores españoles aparecen, salvo contadas excepciones, en revistas militares, están escritos por profesionales del ejército y sólo muy raramente se refieren a temas históricos. A partir de $1962^{9}$, y por espacio de más de treinta años, Domingo Pastor Petit ha sido el gran especialista español en temas de espionaje, el más prolífico, y el único que ha alcanzado cierta notoriedad internacional ${ }^{10}$. A principios de la Transición se produce un discreto primer salto cuantitativo como consecuencia de la publicación de algunos títulos referidos a la historia de los servicios secretos implicados en la Guerra Civil o algún que otro trabajo sobre el espionaje durante el tardofranquismo. La producción crece muy lentamente a lo largo de la década de los ochenta, pero en general sigue siendo muy pobre tanto en número como en cantidad. De hecho, sigue privilegiándose durante largo tiempo la publicación de obras traducidas que, por lo general, son mejor acogidas y con las que se corren menos riesgos editoriales. Además, la Guerra Fría estaba en su punto álgido, y casi todas estas publicaciones se dedicaban al relato pormenorizado de las batallas en la sombra que estaban librando en aquellos años Estados Unidos y la Unión de Repúblicas Socialistas Soviéticas.

2. Desde 1990: La oleada de escándalos en la que se ven envueltos los servicios secretos españoles en los primeros años de la década de los noventa posibilitan que éstos pasen a ocupar por primera vez en la historia de la España contemporánea, y por un tiempo largo

\footnotetext{
9 D. PAstor Petit, Espias en acción, Barcelona, Argos, 1962.

10 Sin embargo, a nuestro juicio, la obra de Pastor Petit, no ha resistido como debiera el paso del tiempo dada su falta de rigor histórico y los «excesos» de su estilo. De todos modos, a pesar de los evidentes déficits metodológicos de sus publicaciones, Pastor Petit sigue siendo hoy en día un autor de referencia obligada en la historiografía española sobre servicios de inteligencia. Por citar sólo un ejemplo, en su Diccionario enciclopédico del espionaje (Madrid, Complutense, 1996) tienen cabida las operaciones claves en la historia de los servicios secretos, las siglas de las grandes organizaciones norteamericanas, soviéticas, británicas, francesas, italianas, españolas, etc, así como los nombres de algunos de los agentes más famosos como Sorge, Philby, Penkovsky, Cicerón, etc.
} 
además, el centro de la escena mediática. De esta situación tan sumamente complicada surge un filón editorial. En 1993 el periodista Fernando Rueda publica La casa: el CESID, agentes, operaciones secretas $y$ actividades de los espias españoles, y el éxito editorial de esta obra lleva a la publicación de otras tres, de temática similar, firmadas por ese mismo autor. Otros periodistas siguen su ejemplo, y la lista de libros sobre los servicios secretos españoles se incrementa considerablemente. $Y$ aunque podría dar la impresión de que se trata del éxito de un subgénero pasajero, los datos editoriales demuestran lo contrario. De hecho, un porcentaje muy elevado de los títulos que hemos recogido corresponden a los últimos doce años, de ahí que pueda afirmarse la existencia de una progresión exponencial de trabajos sobre los servicios de inteligencia en España. Los números actuales nos alejan de la única gran tradición historiográfica reconocida mundialmente, la anglosajona, pero nos acercan a países de nuestro entorno geopolítico como Francia o Italia.

Pese a este notable progreso cuantitativo, la producción contemporánea de los estudios sobre inteligencia presenta todavía graves deficiencias. De este modo, por ejemplo, siguen siendo prácticamente inexistentes las obras de síntesis. Como afirma Carlos Ruiz Miguel, uno de los principales especialistas en los servicios de inteligencia españoles en la actualidad, «está por hacerse la historia de los servicios de inteligencia españoles. No existe ningún estudio histórico completo sobre los mismos, sino estudios fragmentarios» ${ }^{11}$. El carácter poco sistemático y disperso de la producción está lastrando gravemente la evolución de la historiografía española, lo cual redunda en esa impresión de pobreza (teórica y metodológica) que todavía hoy acompaña a este tipo de estudios.

Asimismo, el hecho de que las principales publicaciones hayan sido llevadas a cabo por periodistas influye negativamente en el tipo de discurso empleado en ellas, que aun siendo legítimo, no resulta siempre el más apropiado. En él reinan las urgencias y éstas, a su vez, traen consigo una serie de consecuencias catastróficas para la escritura de la historia, que es esencialmente una disciplina lenta, al imponerle una obligación de resultado inmediato contrario a su naturaleza. El peaje ha sido con toda certe-

11 C. Ruíz Miguel, Servicios de inteligencia y seguridad del estado constitucional, Madrid, Tecnos, [2002], 165. 
za oneroso. Este tipo de literatura ha terminado por desacreditarse a sí misma al ofrecer una historia expeditiva que responde más a los imperativos de la producción mediática que al conocimiento riguroso. Periodismo e historia no tienen la misma relación con el tiempo, ni la misma relación con los hechos, ni los mismos métodos de análisis, y la mezcla de los géneros mantiene la confusión e impide desempeñar convenientemente cada una de las funciones de las que la sociedad tiene necesidad.

Teniendo en cuenta las limitaciones de acceso a la documentación secreta que tienen los historiadores, puede parecer lógico que hayan sido precisamente periodistas de profesión quienes hayan sacado a la luz algunos de los aspectos cruciales de la historia de los servicios secretos españoles. No obstante, también ellos se ven obligados a hilar muy fino, puesto que el secreto de Estado prima sobre el derecho a la información y el secreto profesional, salvo que lo difundido se refiera a la comisión de delitos $^{12}$. Teóricamente, el periodista sólo puede negarse a revelar el origen de las informaciones difundidas si éstas eran conocidas con anterioridad, dado que en ese caso ya no pueden ser consideradas técnicamente como "secretos de Estado". El secreto profesional puede convertirse en un arma de doble filo, puesto que, aunque asegura el cumplimiento de un derecho fundamental del ciudadano, permite, en algunos casos, la difusión de informaciones no suficientemente contrastadas. De modo que el uso que el periodista haga de esta garantía dependerá exclusivamente del «código deontológico» que esté dispuesto a suscribir. Los datos ofrecidos casi nunca vienen acompañados de un soporte documental, así que no nos queda otro remedio que confiar ciegamente en la veracidad de las informaciones. No deben extrañarnos, de este modo, los abusos, la falta de rigor $y$, en cierta medida, la predisposición hacia la defensa de todo tipo de teorías conspiratorias.

La escasez de testimonios de espías españoles contrasta con lo que sucede en otros países (Alemania, Inglaterra, Estados Unidos, Rusia, etc.), en los que los relatos de los protagonistas de la historia de los servicios de inteligencia poseen una mayor y mejor aceptación. Es posible que la propia legislación española referida al delito de revelación de secretos resulte ciertamente disuasoria ${ }^{13}$, sobre todo teniendo en cuenta que, por lo

12 Sentencia del Tribunal Supremo de 4 de abril de 1997. Cit. por M ${ }^{\mathrm{a}}$ C. PÉREZ.VILLALoBos, Derechos fundamentales y servicios de inteligencia, [Granada], Grupo Editorial Universitario, [2002], 95.

13 El Código Penal contiene dos grupos de delitos protectores del secreto de Estado. Por una parte, con carácter general, en los artículos 413 a 418 se castigan las conductas 
que respecta a los funcionarios públicos, se castigan duramente varias conductas lesivas del secreto ${ }^{14}$. En todo caso, el historiador debe afrontar con muchísima precaución la información procedente de estas fuentes de primera mano e intentar interpretarlas correctamente, ya que uno de los problemas inherentes a la memoria personal de los acontecimientos del pasado es su carácter subjetivo y cambiante. Lo que estos protagonistas callan podría ser realmente mucho más trascendental que lo que cuentan, por no hablar, llegado el caso, del recurso a la mentira. Lo ideal sería poder cotejar los testimonios orales con la documentación secreta que haya sido desclasificada, práctica muy poco habitual todavía en la historiografía española.

\section{Guía bibliográfica de estudios sobre inteligencia y espionaje}

\section{Historia moderna de España}

La importancia de los servicios de inteligencia en la Edad Moderna ha sido minusvalorada en muchas ocasiones por la historiografía tradicional. Eclipsado por otros medios de acción política más espectaculares como la diplomacia oficial o la guerra, el espionaje alcanzó durante este largo periodo una importancia considerable y, de hecho, constituye uno de los aspecto fundamentales en el proceso de construcción del Estado moderno. La nómina de investigadores españoles que han estudiado estos temas es relativamente escasa, pero cuenta ya con algunos nombres de cierto peso como Miguel Ángel Echevarría Bacigalupe, Emilio Sola, Carlos J. Carnicer García, Javier Marcos Rivas, David Salinas o Diego Navarro Bonilla, por citar tan sólo a algunos de los más destacados. Se echan en falta los trabajos de síntesis, y de hecho todavía está por escribir la gran monografía que aborde la historia de los servicios de infor-

"de la infidelidad en la custodia de documentos y de la violación de secretos»; por otra, en los artículos 598 a 603 , las de «descubrimiento y revelación de secretos e informaciones relativas a la Defensa nacional».

14 «En primer lugar, la sustracción, destrucción, inutilización u ocultación de documentos cuya custodia tenga encomendada el funcionario; la destrucción o inutilización de los medios dispuestos para impedir el acceso no autorizado a los secretos. En tercer lugar, el acceso o la facilitación del acceso al secreto, sin tener la correspondiente autorización. En cuarto lugar, finalmente, se castiga la revelación del secreto, aspecto éste no comprendido en los anteriores tipos penales». Cit. en C. Ruiz Miguel, Servicios de inteligencia y seguridad del estado constitucional, op. cit., 238-239. 


\section{Los servicios de inteligencia en la historiografía española}

mación españoles en la Edad Moderna. Mientras tanto, debemos contentarnos con los satisfactorios balances que han llevado a cabo Echevarría Bacigalupe o Navarro Bonilla ${ }^{15}$.

En cualquier caso, contamos además con algunas obras publicadas por autores extranjeros que hacen referencia constante a las actividades o a las redes de espionaje de otras potencias de aquellos siglos pero que tenían una gran influencia sobre la Península Ibérica, entre los que cabría destacar las realizadas por Paolo Preto sobre los servicios de inteligencia venecianos; por Alain Hugon sobre las relaciones hispanofrancesas a principios del siglo XVII, o por Lucien Bély acerca del espionaje en tiempos de Luis XIV ${ }^{16}$.

La bibliografía disponible referente al siglo XV es realmente muy exigua. Aparte del volumen correspondiente de la Historia de la Diplomacia Española, de Miguel Ángel Ochoa Brun, que nos ofrece abundantes datos relacionados con actividades secretas en los tiempos de los Reyes Católicos, poco más queda por reseñar ${ }^{17}$.

15 M. Á. EchevarRía Bacigalupe, «El espionaje y las rebeliones de los ss. XVI y XVII en la monarquía hispánica", en W. THOMAS y B. DE GROOG (eds.), Rebelión y resistencia en el mundo hispánico del siglo XVII, Lovaina, Leuven University Press, 1992; D. NAVARRo BonILLA, Los archivos del espionaje: información, razón de Estado y servicios de inteligencia en la Monarquía Hispánica, Salamanca, Cajaduero, 2004. Este trabajo fue merecedor del «Premio Nacional de Defensa» correspondiente al año 2003 en la modalidad de investigación en ciencias históricas relacionadas con el ámbito militar. Cf. igualmente, del mismo autor, «Informes, relaciones y avisos: la producción documental del espionaje hispano en tiempos de guerra (siglos XVI y XVII)», en Revista de Historia Militar 48 (95) (2004), 185-213 y también "Los servicios de información durante la Monarquía Hispánica, siglos XVI y XVII», conferencia inaugural de las Jornadas de Historia Militar citadas en la nota 4.

16 P. Preto, I servizi segreti di Venezia, Milan, Il Saggiatore, 1994; A. Hugon, «L'affaire L'Hoste ou la tentation espagnole (1604)», en Revue d'Histoire Moderne et Contemporaine 42(3) (1995), 355-375; del mismo autor, "Les rendez-vous manqués de Gerard de Raffis: espionnage et retournement ideologique sous le regne de Henri IV», en Revue His. torique 296(1) (1996), 59-82; del mismo autor, «Le renseignement espagnol face à la France a l'aube du XVIIe siècle: vocation internationale et catholicité", en Revue d'Histoire Diplomatique 111 (3) (1997), 247-272; del mismo autor, "La frontiere pyreneenne pendant l'Ancien Regime: un espace sous surveillance. La politique espagnole au debut du XVIIe siecle», en Revue de Pau et du Béarn 27 (2000), 121-149; L. BÉly, Espions et ambassateurs: au temps de Louis XIV, [París], Fayard, 1990.

${ }_{17}$ M. Á. Ochoa Brun, Historia de la Diplomacia Española, Madrid, Ministerio de Asuntos Exteriores, 1995, vol. 4. Habría que citar acaso el trabajo de M. Á. PALLARES JIMÉNEZ, «Conto de los Caballeros del Sueldo, hombres de a pie y espías. Gastos de guerra del año 1463 en Cinco Villas», en Suessetania 15-16 (1996-1997), 124-136; el artículo de 
Para el periodo inmediatamente posterior tampoco hemos encontrado demasiadas referencias, pero si nos circunscribimos al largo reinado de $\mathrm{Fe}$ lipe II, la producción bibliográfica aumenta considerablemente. Algunos trabajos como Tres embajadores de Felipe II en Inglaterra, de Manuel Fernández Álvarez; Espionaje y última aventura de José Nasio (15691574), de Agustín Arce o Anatomía del espionaje, de Domingo Pastor Petit, ponen de manifiesto que durante el reinado filipino se pusieron en marcha mecanismos de control e inteligencia que afectaban a sus relaciones con distintos Estados y regiones del orbe. Enrique García Hernán, en un capítulo de su libro La Armada española en la monarquía de Felipe II y la defensa del Mediterráneo, aborda cuestiones relativas a los medios económicos, los programas, la formación de los capitanes, las organizaciones administrativas de la Armada, los sistemas de comunicaciones, etc. pero también el funcionamiento de las redes de información y espionaje. David García Hernán es autor de otro artículo sobre las actividades informativas desarrolladas en el ámbito mediterráneo. Emilio Sola y José F. de la Peña, por su parte, han estudiado las tramas levantinas y berberiscas en Cervantes y la Berbería, una obra en cuyo capítulo final se analizan las posibles relaciones que el escritor alcalaíno pudo tener con los servicios de información de Felipe II en aquellos territorios; también contiene referencias interesantes un pequeño estudio de Sola sobre el papel de los espías y los correos en la redención de cautivos en la frontera mediterránea. Asimismo, por el volumen de información que nos ofrece sobre las redes de espionaje en esta época, cabe destacar el segundo volumen de Fuentes para la política oriental de los Austrias de J. M. Floristán Imizcoz. Respecto a las actividades de los servicios de espionaje en el ámbito de las relaciones hispanofrancesas durante este periodo, hemos de referirnos en primer lugar a una monografía de Carlos J. Carnicer García y Javier Marcos Rivas titulada Sebastián de Arbizu, espía de Felipe II: la diplomacia secreta española y la intervención en Francia, en la que se desvelan, combinando la narración biográfica con un riguroso análisis histórico, el funcionamiento, la estructura, los métodos y las actividades de la red de espionaje dirigida por

J. Ma PorRo GutiÉRREZ, «Una antinomia protorrenacentista: secreto de estado y divulgación en los descubrimientos lusó-castellanos. La cartografía (1418-1495)» en Anuario de Estudios Americanos 60 (1) (2003), 13-40, en donde se analiza la política de sigilo y de espionaje mutuo desarrollada por portugueses y castellanos en su pugna por el predominio atlántico en el transcurso de aquellos años; o la contribución de L. SECO DE LUCENA PAREDES, «El musulmán Ahmad 'Ulayla, espía de los Reyes Católicos en la Corte granadina», en Miscelánea de estudios árabes y hebraicos 9 (1) (1960), 157. 


\section{Los servicios de inteligencia en la historiografía española}

este espía navarro, entre las que destacaron el intento de captura de Antonio Pérez, refugiado entonces en la corte bearnesa de Pau. Estos mismos investigadores han publicado Espionaje y traición en el reinado de Felipe II: la historia del vallisoletano Martín de Acuña. También merecen ser reseñados en este punto algunos trabajos de Jaime Contreras, Valentín Vázquez de Prada y Miguel Cabañas Agrela ${ }^{18}$.

Asimismo, Flandes ya se había convertido por aquel entonces en terreno especialmente abonado para el desarrollo de este tipo de servicios. Gabrielle Dorren ha tratado la cuestión en alguna de sus investigaciones y ha relatado las peripecias de agentes españoles que desarrollaron sus

18 M. FernÁNDez ÁlVARez, Tres embajadores de Felipe II en Inglaterra, Madrid, Instituto Jerónimo Zurita, 1951; A. ARCE, Espionaje y última aventura de José Nasio (1569. 1574), Madrid, s.n., 1953; D. PASTor Petit, Anatomía del espionaje, Barcelona, Plaza \& Janés, 1970; D. GARCÍA HERNÁN, «Algunas notas sobre el servicio de información de la Monarquía Católica en el Mediterráneo en tiempo de Felipe II», en Espacio, Tiempo y Forma: Historia Moderna 7 (1994), 245-258; E. Sola CASTAÑo y J. F. DE LA PeÑa, Cervantes y la Berbería (Cervantes, mundo turco-berberísco y servicios secretos en la época de Felipe II). Cf. la reseña publicada por A. SÁNCHEZ en Anales cervantinos 33 (1995-1997), 377378, así como el capítulo que le dedica F. MARTínez LAÍNEZ, Escritores espias. La insólita vida de los grandes de la literatura, Madrid, Temas de Hoy, 2004; E. SOla CASTAÑo, "Los que van y vienen: marinos, espías y rescatadores de cautivos en la frontera mediterranea», en Historia 1621 (251) (1997), 50-57; J. M. FLORISTÁN IMIZCOZ, Fuentes para la politica oriental de los Austrias. La documentación griega del Archivo de Simancas (15711621), León, Servicio de Publicaciones de la Universidad, 1988, vol. II, 579-737; C. J. CARnicer García y J. Marcos RIVAS, Sebastián de Arbizu, espía de Felipe II: la diplomacia secreta española y la intervención en Francia, Madrid, Nerea, 1998; J. MaRcos Rrvas y C. J. CARNICER GARCÍA, Espionaje y traición en el reinado de Felipe II: la historia del vallisoletano Martín de Acuña, [Valladolid], Diputación Provincial de Valladolid, 2001. So bre este mismo espía, cf. F. J. SÁNCHEZ CANTÓN, «Un drama bajo Felipe II: la ejecución del espía don Martín de Acuña", en Boletín de Real Academia de la Historia 125 (2) (1949), 187, además la semblanza realizada hace más de un siglo por F. PRIETo, Don Martín de Acuña. Capitán de arcabuceros caballero del hábito de Santiago y espía mayor del Rey de las Españas Don Felipe II (1544-1585). Estudio biográfico, Madrid, M.G. Hernández, 1899; J. ConTRERAS, «Espagne et France au temps d'Henri IV: inquisiteurs, morisques et brigands», en Revue de Pau et du Béarn 17 (1990), 9-57 ; V. VÁzQUEZ DE PRADA, «La embajada española en Francia en la época de Felipe II» en P. FERnÁNDEz ALBADalejo, J. Martínez Millán y V. Pinto Crespo (coords.), Política, religión e Inquisición en la España Moderna. Homenaje a Joaquín Pérez Villanueva, Madrid, Universidad Complutense, 1996, 671-690; M. CABAÑAS AGRELA, «Bernardino de Mendoza. Un espía español en la Corte de Isabel I», Historia 1626 (321) (2003), 8-27; del mismo autor, "La Corte de Isabel I a través de los ojos de un embajador. Fiestas e intrigas», en Historia 1626 (321) (2003), 28-41. 
actividades en los Países Bajos en aquellos años tales como Lorenzo de Villavicencio o Alonso del Canto. Pero sin duda el autor que mejor conoce los entresijos de los servicios de información de la monarquía hispánica en el siglo XVI (y también, y más profundamente todavía, en las primeras décadas del XVII) es Miguel Ángel Echevarría Bacigalupe, quien enfatiza las actividades de personajes como Juan de Gauna, Alberto Struzzi y Ortuño de Urízar en alguna de sus obras, como por ejemplo Flandes y la monarquía hispánica, 1500-1713. Sin embargo, otros especialistas en este periodo, como René Vermeir, han criticado la atribución de una importancia "desproporcionada» al funcionamiento de la red española de inteligencia secreta, afirmando, entre otras cosas, que «el servicio secreto español (..) ni siquiera resultó capaz de detectar las amenazas de tormenta en casa propia y distó mucho de desempeñar un papel estratégico de importancia ${ }^{19}$.

Sobre el espionaje morisco también hay algunos trabajos publicados, entre los que destacamos los de María del Carmen Calero Palacios, Serafín de Tapia o Javier Castillo Fernández, quien traza una biografía del sacerdote Francisco de Torrijos haciendo hincapié en su ambiguo papel en la rebelión de las Alpujarras, probablemente como espía en ambos bandos ${ }^{20}$.

Por supuesto, no faltan los estudios en los que se señala la importancia de las labores de información en la preparación de algunas de las más famosas batallas en las que se vio implicada la monarquía hispánica en

19 G. DORREN, «La tolerancia, esa perversa opinión: el espionaje español en Flandes en vísperas de la guerra (1564-1566)», Historia 1618 (209) (1993), 48-62; M. Á. ECHEVARRÍA BACIAGLUPE, La diplomacia secreta en Flandes, 1598-1643, Bilbao, Servicio Editorial. Universidad del País Vasco, 1984; del mismo autor Flandes y la monarquía hispánica, 1500-1713, Madrid, Sílex, 1998 ( $c f$. la reseña de este libro firmada por René VERMEIR y publicada en Foro Hispánico 22/1 (2002), 177-179); del mismo autor, "Economía e información en el área del Mar del Norte (primera mitad del siglo XVII)», en Investigaciones Históricas. Época Moderna y Contemporánea 7 (1988), 27-42; del mismo autor, «Manuel Sueiro, espía en Flandes", en Historia 1613 (141) (1988), 43-52; del mismo autor, «Espionaje en Flandes durante el reinado de Felipe II», en A. FernándEZ DE Molina (ed.), Antonio Pérez. Semana Marañón '98. Zaragoza, Fundación Gregorio Marañón, Instituto Fernando el Católico; Excma. Diputación de Zaragoza, 1999, 69-88.

${ }^{20} \mathrm{M}^{a} \mathrm{C}$. Calero Palacios, "Contribución al estudio del espionaje morisco a través de un documento del archivo de la Alhambra", en Cuadernos de la Alhambra 14 (1978), 147 150; S. DE TAPIA, «Las redes comerciales de los moriscos de Castilla la Vieja: un vehículo para sus "complicidades"”, en Studia Histórica. Historia Moderna 10-11 (1992-1993), 231-243; J. CASTILlo FERNÁNDEZ, «El sacerdote morisco Francisco de Torrijos: un testigo de excepción en la rebelión de las Alpujarras», en Chronica Nova 23 (1996), 465-492. 


\section{Los servicios de inteligencia en la historiografía española}

aquellos tiempos. En este sentido, hemos de referirnos al libro de Rafael Vargas-Hidalgo, La batalla de Lepanto: según cartas inéditas de Felipe II, don Juan de Austria y Juan Andrea Doria e informes de embajadores y espías o un breve artículo de divulgación publicado Enrique García Hernán sobre esa misma batalla, del mismo modo que sobre la actuación de los servicios secretos en el Desastre de la Armada Invencible habría que citar los trabajos de Francisco Felipe Olesa Muñido, Simón Adams, Hugo O'Donnell y Duque de Estrada o de Esteban Morán Torres, quien por cierto pone de manifiesto la importancia de la criptografía en el resultado final de la batalla y el papel que jugaron personajes como Francis Walsingham o Bernardino de Mendoza. También debemos de reseñar en este punto un artículo de Francisco de Borja Medina sobre la empresa de Inglaterra ${ }^{21}$.

Relativamente prolíficas han sido a su vez las aportaciones referidas a los casos de espionaje producidos en territorio vasco-navarro durante el siglo XVI. José María Satrústegui presentó una colección de documentos inéditos muy interesantes tanto por su antigüedad y extensión como por la originalidad del tema en un artículo que provocó una polémica erudita con Josu Oregui Aramburu, quien por su parte propuso algunas correcciones de lectura e interpretación de aquellos documentos. Por otra parte, José Manuel Floristán Imizcoz elaboró otro artículo a partir de veinte cartas procedentes del Archivo General de Simancas, también relacionadas con varios casos de espionaje militar en la frontera vascofrancesa, pero esta vez fue Satrústegui quien sugirió algunas puntualizaciones al citado estudio, proponiendo nuevos análisis lingüísticos ${ }^{22}$.

21 R. VARGas-Hidalgo, La batalla de Lepanto: según cartas inéditas de Felipe II, don Juan de Austria y Juan Andrea Doria e informes de embajadores y espias, Santiago de Chile, ChileAmérica CESOC, 1998; E. GARCÍA HERnÁN, "Espionaje en la batalla de Lepanto», Historia 1627 (332) (2003), 9-41; F. F. OLESA MUÑDO, «Algunas consideraciones en torno a la Gran Armada», en Revista de Historia Naval 1 (1983), 31-93 (cf. especialmente los epígrafes "Información, posta y cifra en la monarquía española" y "Los órganos de información ingleses»); S. ADAMS, «La batalla que nunca existió. Reconsideración sobre la estrategia de la Campaña de la Armada», en Revista de Historia Naval 23 (1988), 73-88; H. O'DONNELL Y DUQUE DE ESTRADA, «El secreto, requisito para la empresa de Inglaterra de 1588 (II)", en Revista de Historia Naval 2 (7) (1984), 63-74; E. Morán TORRES, «Los espías de la Invencible», en Historia 1613 (152) (1988), 31-37; F. de B. MEDINA, S. J., «Escocia en la estrategia de la empresa de Inglaterra. La misión del P. William Crichton cerca de Felipe II (1590-1592)", en Revista de Historia Naval 64 (1999), 53-110 (esp. el epígrafe «Los espías e informadores»).

22 J. $\mathrm{M}^{a}$ SATRÚstegut, "Miscelánea de textos antiguos vascos», en Fontes Linguae Vasconum 23 (58) (1991), 283-299; J. OREGUT ARANBURO, «Textos antiguos vascos. Acotaciones", en Fontes Linguae Vasconum 24 (60) (1992), 263-270; J. M. FloRisTán ImizCO, 
Respecto a la historia del espionaje español durante las primeras décadas del siglo XVII tenemos que hacer referencia en primer lugar a un clásico, el trabajo del historiador americano Charles Howard Carter, The Secret Diplomacy of the Habsburgs, 1598-1625, todavía hoy en día la única obra que presenta una visión de conjunto sobre el reinado de Felipe III. Sorprende comprobar que apenas hayan sido estudiadas las actividades de información y espionaje de Francisco de Quevedo y Villegas, sobre todo si tenemos en cuenta que ha sido considerado por algunos autores como el mejor agente secreto que ha tenido España a lo largo de su historia. Entre las escasas excepciones, cabe destacar el capítulo que le dedica Fernando Martínez Laínez en su libro Escritores espías. Algo parecido sucede con Diego Sarmiento de Acuña, quien, a pesar de ser el encargado de dirigir los servicios secretos españoles en este periodo (organizando unas redes que tendían sus tentáculos por toda Europa desde Londres y logrando la desarticulación de los complots dirigidos contra los intereses españoles), tampoco tenemos constancia de la publicación de ningún estudio monográfico en el que se relaten detalladamente sus actividades. Por lo que se refiere a la bibliografía nacional, tenemos que volver a hacer una vez más referencia a Echevarría Bacigalupe, autor de una obra titulada La diplomacia secreta en Flandes, 1598-1643. En cuanto al resto, apenas podemos citar un artículo de José Ramón Fernández Suárez en el que se tratan cuestiones relacionadas con estas actividades en el ámbito diplomático hispano-británico, protagonizadas por el conde de Gondomar, el conde de Bristol, C. Cornwalis o L. de Carvajal, así como una interesante contribución de Jesús Carrasco Vázquez en la que se analiza el lucrativo y sucio negocio del vellón en el que participaron amplias capas de la sociedad castellana y su relación con el asesinato de un espía inglés al servicio de España llamado Jorge Cotón o la persecución inquisitorial de otro espía de la Corona, el morisco Gabriel de Carmona. También a caballo entre el final del siglo XVI y principios del XVII se sitúa un trabajo de Fernando Rodríguez Mediano y Mercedes García-Arenal en el que tratan de reconstruir la vida de Diego de Urrea, uno de los traductores de árabe más importantes de la época en España e intermediario y espía en asuntos marroquíes ${ }^{23}$.

\footnotetext{
«Conflictos fronterizos, espionaje y vascuence a finales del siglo XVI: 20 documentos iné ditos», en Fontes Linguae Vasconum 25 (63) (1993), 177-219; J. M ${ }^{a}$ SATrusteGUI, «Relectura de los textos vascos de espionaje del siglo XVI», en Fontes Linguae Vasconum 25 (64) (1993), 443-475.

${ }^{23}$ Ch. H. CARTER, The Secret Diplomacy of the Habsburgs, 1598-1625, Nueva York, Columbia University Press, 1964; F. MarTínez LAÍnEZ, Escritores espías: la insólita vida
} 
Los servicios de inteligencia en la historiografía española

También son escasos y excesivamente locales los estudios sobre estas redes durante el reinado de Felipe IV. Antoni Simon i Tarres ha estudiado algunos de los conflictos políticos relacionados con las actividades de espionaje llevadas a cabo por personajes como Gaspar de Bonifaz en Cataluña hacia los años 1635-1640. A su vez, en el contexto global de la guerra entre los Habsburgo españoles y los Borbones franceses, Antonio Muñoz González y Josep Catà i Tur le han dedicado un estudio específico a la capitulación de Barcelona de octubre de 1652, en el que se destacan diversos aspectos de este episodio como por ejemplo el uso masivo de espías y confidentes en ambos lados. Abundantes informaciones sobre las actividades de los servicios de información del Real Ejército de Extremadura durante la rebelión portuguesa aparecen en un trabajo de Fernando Cortés Cortés. Por su parte, Miguel Gómez del Campillo publicó hace años un artículo sobre la figura del Espía Mayor. Don Juan de Valencia, pintoresco peruano que vivió en la Corte y que llegó a ocupar este cargo durante el reinado de Felipe IV, también ha sido objeto de algunas breves investigaciones, como por ejemplo El limeño don Juan de Valencia el del Infante. Preceptista taurino y espía mayor de Castilla, de Guillermo Lohmann Villena o Don Juan de Valencia, espía mayor de Felipe IV y torero, de María del Carmen Pescador del Hoyo. Por último, Balbina Prior Barbarroja ha publicado un artículo las relaciones entre la famosa espía Aphra Behn y el teatro español ${ }^{24}$.

secreta de los grandes de la literatura, Madrid, Temas de Hoy, 2004; J. R. Fernández SUÁREZ, «La embajada inglesa en Madrid y la española en Londres (1607-1614)», en Revista de Filología Inglesa 6 (1976), 81-138; J. CARRASCO VÁZQUEZ, "Contrabando, moneda y espionaje (el negocio del vellón: 1606-1620)" en Hispania 57-3 (197) (1997), 1081-1105; F. RODRÍGUEZ MEDIANO y M. GARcíA-ARENAL, «Diego de Urrea y algún traductor más: en torno a las versiones de los "plomos»", en Al-Qantara. Revista de Estudios Árabes, 23 (2) (2002), 499-516.

${ }^{24}$ A. SIMON I TARRES, "Els espies d'Olivares a Catalunya», en L'Avenç 198 (1995), 18 21; A. MuÑoz GonzÁLEZ y J. CATÁ I TuR, "Setge o capitulació de Barcelona el 1652", en Quaderns d'Història 5 (2001), 231-247; F. CORTÉS CORTÉS, «Extremadura a mediados del siglo XVII: II. El Real Ejército de Extremadura y su presión sobre la región", en Alcántara. Revista del Seminario de Estudios Cacereños 11 (1987), 7-20; M. GóMEZ DEL CAMPILLO, «El espía Mayor y el Conductor de Embajadores», en Boletín de la Real Academia de la Historia 119 (1/2) (1946), 317; G. Lohmann VIllenA, El limeño don Juan de Valencia el del Infante. Preceptista taurino y espía mayor de Castilla, Madrid, Instituto «Gonzalo Fernández de Oviedo» - CSIC, 1952; M $^{\mathrm{a}}$ C. PEsCADOR DEL Hoyo, Don Juan de Valencia, espía mayor de Felipe IV y torero, Madrid, Instituto de Estudios Madrileños, 1987; de la misma autora, "La espada de Felipe IV en la armería del Palacio Real de Madrid», en Reales Sitios 26 (101) (1989), 61-62; B. PrIor BARBARrojA, «La conexión española de la espía 
El reinado de Carlos II de España coincide con el período político más inestable de la Europa del siglo XVII, como consecuencia fundamentalmente de la rivalidad de los movimientos diplomáticos y militares provocados en gran parte por la Francia de Luis XIV. David Salinas ha publicado sobre este periodo dos obras de consulta obligada: La Diplomacia española en las relaciones con Holanda durante el reinado de Carlos II (1665-1700) y Espionaje y gastos en la diplomacia española (1663-1683) en sus documentos, obra ésta con la que el autor pretende poner al descubierto los mecanismo del gobierno investigando dos aspectos que causaron daño y preocupación en Francia, a saber, el servicio de espionaje y los gastos de las embajadas en ese periodo ${ }^{25}$.

Por lo que se refiere al reinado de Felipe $V$, poco o nada podemos reseñar. De hecho, no existe ningún estudio monográfico sobre la figura de Ana María de la Tremouille, princesa viuda de Ursini, a la que Luis XIV había enviado a España para que vigilase de cerca a su nieto. Por el contrario, como ha demostrado Cezary Taracha, el espionaje alcanzó en ese periodo una importancia crucial, sobre todo si tenemos en cuenta el empeño del marqués de la Ensenada en este ámbito, quien, a pesar de no ser el titular de la secretaría de Estado, llegó a crear su propia red de informantes al margen de aquella. Isidoro Pinedo ha estudiado la compleja situación de las relaciones hispano-británicas tras la Guerra de los Siete Años, finalizada en 1763, en un trabajo en el que se alude a las sospechas de Manuel de Roda, basadas en informes enviados por sus espías, de que Inglaterra estaba utilizando la cuestión jesuítica para hostigar a España. Pedro Voltes Bou también se refiere a algunas de las actividades de espionaje durante el gobierno del marqués de Floridablanca. José Francisco Pérez Berenguel ha tratado las opiniones vertidas por Alexander Jardine, uno de los mayores conocedores británicos de la realidad política y militar española de finales del siglo XVIII, tomando como base los informes inéditos que este personaje enviaba periódicamente a su gobierno durante su etapa de espía en España. Demetrio Ramos ha anali-

Aphra Behn (1640-1689) con el teatro español: Torres Naharro, Gil Vicente, Lope de Rue da, Calderón, Cervantes...», en D. MarTínez Torrón (ed.), Sobre Cervantes. Alcalá de Henares, Centro de Estudios Cervantinos, 221-230 (sobre Aphra Behn, cf. también el capítulo que le dedica F. MARTÍNEZ LAÍNEZ, Escritores espias, op. cit.).

25 D. Salinas, La Diplomacia española en las relaciones con Holanda durante el reir nado de Carlos II (1665-1700), Madrid, Dirección General de Relaciones Culturales, 1989; y del mismo autor, Espionaje y gastos en la diplomacia española (1663-1683). En sus documentos. Valladolid, Ámbito, 1994. 
zado el papel jugado por la isla de Madeira como centro del espionaje español en el marco de las relaciones con Inglaterra. Este autor también ha abordado cuestiones relacionadas con la intervención de los servicios de inteligencia en el transcurso del proceso de Independencia de Estados Unidos, poniendo de relieve la actuación de personajes como el marqués de Grimaldi, José de Gálvez o el marqués de la Torre en Florida, La Habana o Jamaica en el transcurso de ese año crucial. La producción bibliográfica española sobre los servicios de información en el ámbito de la historia moderna de América es muy escasa y, de hecho, apenas existen aportaciones que aborden esta temática. A pesar de este déficit, además del artículo de Ramos Pérez debemos citar si acaso algún trabajo de Jorge Victoria Ojeda ${ }^{26}$.

Lo que sí proliferan son los estudios relativos al ámbito del espionaje industrial. Algunos de ellos, por cierto, se refieren a un marco cronológico relativamente temprano, como es el caso de un trabajo de José Antonio García-Diego dedicado a Agustín de Betancourt. Sin embargo, los dos personajes de los que abundan más estudios en el ámbito del espionaje industrial dieciochesco son Jorge Juan y Antonio de Ulloa. Cabe destacar, en este sentido, el balance llevado a cabo por Antonio Lafuente y José Luis Peset Reig. Por lo que se refiere a Jorge Juan, la Revista General de Marina le dedicó un monográfico especial con motivo del segundo centenario de su muerte, en el que sobresalen las aportaciones de Juan García-Frías, Dalmiro de la Válgoma y Díaz Varela, José Luis Morales Hernández, Pascual O’Dogherty y José Fernández Gaytán. Las ac-

26 C. TARACHA, "El Marqués de la Ensenada y los servicios secretos españoles en la época de Fernando VI», en Cuadernos de Investigación Histórica: Brocar 25 (2001), 109121; I. PINEDO, «¿Intromisión británica a propósito de la extinción de los jesuitas?», en Revista de Historia Moderna 15 (1996), 201-212; P. VolTEs BoU, «Tomás Hussey y sus servicios a la política de Floridablanca», en Hispania 19 (74) (1959), 92-141; J. F. PÉREZ BERENGUEL, Una visión crítica de la España del XVIII: la obra epistolar de Alexander Jardine, Oviedo, Universidad de Oviedo, 1996 (tesis doctoral); del mismo autor, "Un espía inglés en la Corte de Carlos III: el ejército y las relaciones hispano-británicas (17761779)", en Studia Histórica. Historia Moderna 22 (2000), 213-226; D. RAMos PÉREZ, "Madeira, centro del espionaje español sobre las actividades británicas en el siglo XVIII», en Actas do II Colóquio Internacional de História da Madeira. Funchal, Comissao Nacional para a Comemoraçao dos Descobrimentos Portugueses, 1990, 191; D. RAMOs PÉREZ, «Puntos americanos de fricción en 1776: la Habana, centro del espionaje español», en Hispanoamerica hacia 1776. Madrid, CSIC, Instituto Gonzalo Fernández de Oviedo - Instituto de Cooperación Iberoamericana, 1980, 131-181; J. VICTORIA OJEDA, «Piratería y estrategia defensiva en Yucatán durante el siglo XVIII", en Revista Complutense de Historia de América 20 (1994), 129-144. 
tividades relacionadas con este tipo de espionaje también han sido resaltadas por José Merino, Francisco Aguilar Piñal y Juan Helguera Quijada. Este último es autor además de una tesis doctoral titulada El Estado y la modernizacion de la industria metalúrgica española en el siglo XVIII: las fundiciones de artillería, de la que nos interesa especialmente el estudio minucioso de las misiones de espionaje e información industrial que se llevan a cabo por toda Europa en lo que a la fabricación de cañones se refiere. Por su parecido temático debemos señalar también la tesis de María Dolores Herrero Fernández-Quesada, titulada Ciencia y milicia en el siglo XVIII: Tomás de Morla, artillero ilustrado, un personaje que recorrió Europa en el desempeño de una comisión facultativa que encubría una meditada misión de espionaje industrial. Por último, ciñéndonos al ámbito de la historia del espionaje industrial en el País Vasco, debemos citar la obra de Inés Pellón González y Pascual Román Polo, autores de La Bascongada y el Ministerio de Marina. Espionaje, ciencia y tecnología en Bergara (1777-1783), una obra en la que se presenta la correspondencia que mantuvieron destacados personajes vinculados a ese ministerio y que revela aspectos inéditos de las actividades que desarrollaron en aquellos años un conjunto de espías, científicos y técnicos de gran talla que se dieron cita en Bergara bajo el impulso del Conde de Peñaflorida y el Marqués de $\operatorname{Narros}^{27}$.

\footnotetext{
27 J. A. GARCÍA-Diego, "Agustín de Betancourt como espía industrial», en Actas del IV Congreso de la Sociedad Española de Historia de las Ciencias y de la Técnicas, Valladolid, 22-27 de septiembre de 1986, Valladolid, Junta de Castilla y León, Consejería de Cultura y Bienestar Social, 1988, 105-125; A. LAfuente y J. L. Peset ReIG, "Política científica y espionaje industrial en los viajes de Jorge Juan y Antonio de Ulloa (17481751), en Melanges de la Casa de Velázquez 17 (1981), 233-262; J. GARcía-FríAs, «Razón histórica del examen marítimo», en Revista General de Marina (monográfico especial dedicado a «Jorge Juan y Santacilia, 1773-1973») 184 (6) (1973), 643-653; D. DE LA VÁLGOMA Y DIAZ VARELA, «Don Jorge Juan y Santacilia: sus probanzas nobiliarias», en Revista General de Marina 184 (6) (1973), 655-661; J. L. MoRAles HERNÁndEZ, «Jorge Juan, en Londres", en Revista General de Marina 184 (6) (1973), 663-670; P. O'DoGHERTY, "Jorge Juan y la ciencia naval española en el siglo XVIII», en en Revista General de Marina 184 (6) (1973), 671-689; J. FERNÁNDEZ GAYTÁN, «Un marino, embajador en la corte de Marruecos (1767)», en Revista General de Marina 184 (6) (1973), 691-704; J. MeRINo, «La misión de Antonio de Ulloa en Europa», en Revista de Historia Naval 4 (1984), 5-22; Francisco Aguilar Piñal, "Antonio de Ulloa y Sevilla", en M. Losada y C. Varela (eds.), $I I$ Centenario de don Antonio de Ulloa, Sevilla: Escuela de Estudios Hispanoamericanos Archivo General de Indias, 1995, 45-57; Juan HELguera QUIJADA, «Antonio de Ulloa en la época del marqués de la Ensenada: del espionaje industrial al Canal de Castilla (17491754)», en M. Losada y C. VARELA (eds.), II Centenario de don Antonio de Ulloa, op. cit.;
} 
Los servicios de inteligencia en la historiografía española

\section{Historia contemporánea de España}

En 1814 fueron publicados en París los Voyages d'Ali Bey El Abbassi en Afrique et en Asie pendant les années 1803, 1804, 1805, 1806 et 1807, un libro en el que se relataban las actividades de espionaje llevadas a cabo por un agente que pudo recorrer Marruecos, Trípoli, Grecia, Chipre y Egipto haciéndose pasar por un príncipe abasida llamado Ali Bey. La verdadera identidad del falso príncipe resultó ser la del botánico catalán Domingo Badía y Leblich, que estuvo trabajando durante varios años como informador de Manuel de Godoy y de José I. El carácter exótico y ciertamente sorprendente del personaje explican la amplísima repercusión que sus aventuras han tenido sobre la producción bibliográfica española, convirtiéndose de hecho en uno de los hitos fundamentales de la historia del espionaje en España. El libro fue traducido enseguida al castellano y ha conocido múltiples reediciones, entre las que debemos reseñar la que han llevado a cabo Celsa C. García Valdés y Michael McGaha, Ali Bey en Marruecos: Tragedia en cinco actos o la última que ha aparecido por el momento en el mercado editorial español, Viajes de Ali Bey, publicada en 2001. El personaje ha dado lugar además a un buen número de estudios biográficos, entre los que cabe destacar los de José Poch Noguer, Augusto Casas, Joan Mercader Riba y, muy recientemente, Ali Bey, viajero de las Luces, de Juan Luis Tapia. Por lo que a los artículos de divulgación se refiere, hemos de citar, entre otros, los elaborados por Mikel de Epalza, A. García-Wehbe, Jacobo García Blanco-Cicerón, Michael McGaha o José Uxó Palasí. Además, Ali Bey ha sido objeto de varias exposiciones, motivo por el cual también están disponibles algunos catálogos ${ }^{28}$.

J. HELgUERA QUIJADA, El Estado y la modernización de la industria metalúrgica española en el siglo XVIII: las fundiciones de artillería, Valladolid, Universidad de Valladolid, 1986 (tesis doctoral); M $^{2}$ D. HeRrero FERNÁNDEZ-QuesadA, Ciencia y milicia en el siglo XVIII: Tomás de Morla, artillero ilustrado, Madrid, Universidad Complutense, 1988 (tesis doctoral); I. PELLón GONZÁlez y P. ROMÁN POLO, La Bascongada y el Ministerio de Marina. Espionaje, ciencia y tecnología en Bergara (1777-1783), Bilbao, Real Sociedad de Amigos del País, 1999.

28 BADÍA Y LEBLICH, Voyages d'Ali Bey El Abbassi en Afrique et en Asie pendant les années 1803, 1804, 1805, 1806 et 1807, París, Didot L'Ainé, 1814. De las sucesivas reediciones, podemos citar algunas: Viajes del príncipe Ali Bey el Abbassi en Marruecos, Trípoli, Chipre, Egipto, Arabia, Siria y Turquía, realizados en los años 1803 a 1807, escritos por el mismo, e ilustrados con mapas y numerosos grabados, Madrid, [s.n.], [s.a.]; Viajes de Ali Bey el Abbasi por Africa y Asia durante los años 1803-1807, París, Librería de los 
Como es de esperar, la Guerra de Independencia fue un campo abonado para el desarrollo de las actividades de espionaje y, por ello, resulta todavía más sorprendente que contemos con tan pocos estudios previos que hagan referencia a este periodo, si exceptuamos la pequeña síntesis que ha publicado Andrés Cassinello Pérez bajo el título «Los servicios de información en la Guerra de la Independencia». El resto de trabajos que hemos localizado, sin negar su interés, resultan excesivamente particulares o se refieren a aspectos demasiado concretos. En cualquier caso, debemos reseñar un artículo de Francisco Miranda Rubio en el que se describen las actividades de la guerrilla, la estrategia militar o de espionaje

SS. D. Vicente Salvá e hijo, 1836; Viajes de Ali Bey el Abbasi por Africa y Asia durante los años 1803-1807, Valencia, Mallen, 1836; Los viajes de Ali Bey a través del Marruecos oriental. Madrid, Imprenta del Patronato de Huérfanos de Intendencia e Intervención Militares, 1919 (con anotaciones y comentarios a cargo de I. de las Cagigas); Ali Bey el Abbasi: Viatges, Barcelona, Barcino, 1926-1927 (traducción al catalán de F. De Rupiá); Viajes por África y Asia realizados y explicados por Domingo Badia y Leblich utilizando el nombre de príncipe Ali Bey el Abbassí, Barcelona, Olimpo, 1943 (con un prólogo de G. Díaz-Plaja); Viajes de Ali Bey el Abbassi, Madrid, Instituto de Estudios Africanos [Ares], 1951 (edición preparada por Hipólito Rodríguez de la Peña y Julio Romano); Viajes del principe Ali Bey el Abbassi en Marruecos, Trípoli, Chipre, Egipto, Arabia, Siria y Turquia: realizados en los años 1803 al 1807, escritos por el mismo e ilustrados con mapas y numerosos grabados, Madrid, El Museo Universal, 1982; Viajes, Palma de Mallorca, Barcelona, José J. Olañeta Editor, 1982 (incluye un prólogo firmado por J. Goytisolo); Viajes por Marruecos, Madrid, Editora Nacional, 1985 (edición a cargo de Salvador Barberá); C. C. García Valdés y M. McGaHa, Ali Bey en Marruecos: Tragedia en cinco actos, Pamplona, Ediciones Universidad de Navarra, Eunsa, 1999; Viajes de Ali Bey. Barcelona, Editorial Óptima, 2001.

Por lo que a la literatura crítica se refiere, $c f$. J. Poch NogUER, Ali-Bey: vida aventurera de un explorador español, Barcelona, Araluce, 1929; A. CASAS, Ali-Bey. Vida, viajes $y$ aventuras de D. Domingo Badia, Barcelona, Luis Miracle, 1943; J. MERCADER RIBA, Domènec Badia "Ali-Bey": un aventurer català al servei de Godoy $i$ de Josep I, Barcelona, Rafael Dalmau, 1960; J. L. TAPIA, Ali Bey, viajero de las Luces, [Granada], El Legado Andalusí, 2000; M. de EPALZA, «Autour d'un centenaire: le voyageur espagnol Domingo Badia ('Ali Bey al-Abbâsi, 1767-1818)", en Tunisie, Túnez, Institut des Belles Lettres Arabes, 1960, 51-61 ; A. GARCÍA-WEHBE, "Contribution à la biographie de Badía y Leblich alias Ali-Beyn, en Revue des langues romanes 81 (1) (1974), 221; J. GARCíA BLANCO-CICERÓN, «Ali Bey, un espía en la corte de Marruecos. Historia y aventuras del "Lawrence" hispano", en Historia 167 (73) (1982), 20-30; M. MCGAHA, "Domingo Badía (Ali Bey) en Marruecos», en Espacio, Tiempo y Forma. Historia Contemporánea 9 (1996), 11-42; J. Uxó PALASÍ, «Alí Bey El Abbasi, un informador español en el mundo árabe», en Revista de Historia Militar, en prensa; A. LóPEz (coord.), Alí Beí: un pelegrí català per terres de l'Islam, Barcelona, Proa, 1996; Alí Beí: un pelegrí per terres de l'Islam, Valencia [etc.], Diputació de Valencia, Area de Cultura [etc.], 2000. 
que llevaron a cabo Francisco Javier Espoz y Mina o Javier Mina en Navarra entre 1808 y 1812; un pequeño trabajo de Gerardo Dufour en el que se traza un bosquejo biográfico de Luis Gutiérrez y se pone de relieve su condición de agente secreto de Napoleón; una contribución de José María Martí Bonet; una ponencia de Carlos Posac Mon sobre las redes de espías en Tarifa durante la guerra o una breve biografía de Rosa Aguado, una mujer que llevó a cabo actividades de espionaje en la zona de Valladolid en torno a 1811, publicada por Jorge Sánchez Fernández ${ }^{29}$.

Las lagunas historiográficas se hacen todavía más evidentes durante los tiempos de paz. De hecho, para el periodo fernandino, cabe citar únicamente un trabajo de Martín Turrado Vidal en donde se hace referencia a cuestiones relacionadas con la administración del Estado, la represión política, la policía y las actividades de los agentes secretos al servicio de Fernando VII durante la década ominosa. No hemos encontrado ni un sólo estudio sobre estas cuestiones referidas a las fases pacíficas del reinado isabelino. Las guerras carlistas trajeron consigo el desarrollo de varios servicios de información y espionaje en ambos contendientes, pero los investigadores especializados en el carlismo tampoco han mostrado hasta ahora demasiado interés por el estudio en profundidad de estas redes. Sin embargo, a pesar de este déficit historiográfico, uno de los protagonistas de la guerra, Eugenio de Avinareta, se ha convertido en uno de los grandes hitos de la historia del espionaje en España, de ahí que, para este caso particular, contemos con algunos estudios importantes. En este sentido resulta indispensable que hagamos una referencia explícita a Pío Baroja, quien dedicó veintidós años de su vida (1912-1934) y un

\footnotetext{
29 A. CAssinello PÉRez, «Los servicios de información en la Guerra de la Independencia» en Ejército 654 (1994), 75-102 (una de las escasísimas muestras de interés de los militares españoles por el estudio de la Historia, que, desde luego no abunda en los sumarios de las revistas militares españolas); del mismo autor, "Aventuras de los servicios de información durante la Guerra de la Independencia», que saldrá publicado próximamente en el número monográfico que la Revista de Historia Militar citado en la nota 4; F. MIRANDA RUBIO, "El guerrillero navarro y su trascendencia", en Príncipe de Viana 43 (165) (1982), 439-464; G. DufouR, «Andanzas y muerte de Luis Gutiérrez, autor de la novela "Cornelia Bororquia"», en Caligrama. Revista Insular de Filología 2 (2) (1987), 8396; J. M MaRTi BoneT, "Dos clergues enigmatics: Pere Coret, acusat d'espia, i Serafí Llo rens, acusat de colllaboracionista durant la invasiò francesa", en Anuari de la Societat d'Estudis d'Història Eclesiàstica Moderna i Contemporània de Catalunya (1988), 27-57; C. Posac Mon, «Tarifa, base de espionaje en la Guerra de la Independencia (1810-1812)», en Almoraima. Revista de estudios Campogibraltareños 13 (1995), 319-330; J. SÁNCHEZ FERNÁNDEZ, "La Rosita: una espía española en la Guerra de la Independencia», en Historia 1622 (269) (1998), 58-61.
} 
enorme esfuerzo de investigación a escribir una serie de novelas históricas organizadas alrededor de la vida de ese espía en una serie titulada Memorias de un hombre de acción. La popularidad que adquirió este personaje a partir de la publicación de la saga barojiana quizás explique la relativa profusión de estudios sobre su vida, como el que le dedicó el hispanista francés Marcel Bataillon, con datos casi exclusivamente históricos, o el de José Luis Castillo Puche, quien realizó una revisión histórica de la obra de Baroja en su obra Memorias intimas de Avinareta, o Manual del Conspirador (Réplica a Baroja). Por lo que se refiere a la historiografía de los últimos treinta años, únicamente podemos reseñar cuatro pequeñas contribuciones, todas ellas relativas a la Primera guerra carlista: María del Carmen Simón Palmer ha estudiado algunas actividades secretas a partir de la correspondencia que mantuvieron el propio Avinareta y Agustín Fernández de Gamboa; Francisco Asín Remirez de Esparza amplió el relato de las peripecias de esos mismos agentes secretos e incluyó el de otros como José Antonio de Muñagorri, Ramón Cabrera o Clemente Baranda; Alfonso Bullón de Mendoza y Gómez de Valugera se ha centrado en el estudio de las acciones de personajes como Diego Abad, Luis Ortega Morejón, José Anselmo Pasquier o Pedro Márquez, y José Ramón Urquijo Goitia ha esbozado las líneas generales del funcionamiento de los servicios de información en el transcurso de esa guerra ${ }^{30}$.

Ninguna referencia importante que reseñar referida al Sexenio revolucionario, y ciertamente muy pocas para el largo periodo de la Restauración. Las escasas excepciones proceden del estudio de la cuestión colonial y, más concretamente, de la guerra de Cuba, que han propiciado la elaboración de algunos trabajos, si bien es cierto que tampoco demasiado

${ }^{30}$ M. TuRRado VIDAL, "Los primeros fondos reservados: dinero para la represión en la ominosa década", Historia 1619 (220) (1994), 39-45; P. BAROJA, Memorias de un hombre de acción; edición dirigida por J. C. MAINER, Barcelona, Círculo de Lectores, 1997; M. BATALlon, "Para la biografía de un héroe de novela (Eugenio de Avinareta)", en Revista de Filologia Española 18 (1931); J. L. CAstillo Puche, Memorias intimas de Avinareta, o Manual del Conspirador (Réplica a Baroja), Madrid, Biblioteca Nueva, 1952; Ma del C. SIMÓN PALMER, «El espionaje liberal en la última etapa de la primera guerra carlista: nuevas cartas de Avinareta y de F. de Gamboa», en VV. AA., Estudios sobre la España liberal, 1808-1868, Madrid, Hispania, 1973, 289-380; F. AsÍn REMIREZ DE EsPARZA, «El espionaje durante la primera guerra carlista», en Aportes. Revista de historia contemporánea 14 (1990), 4-10; A. Bullón DE MENDoza y Gómez de VAlugera, «Agentes carlistas en España", en Aportes. Revista de Historia Contemporánea 16 (1991), 72-76; J. R. URQUIJO GoITIA, "Servicios de información durante la I Guerra Carlista», en Revista de Historia Militar (en prensa). 
abundantes. Luis Urteaga, Françesc Nadal y José Ignacio Muro han es tudiado la fundación y las actividades iniciales de la Comisión de Estado Mayor en Marruecos, creada por el Depósito de la Guerra con el fin de realizar diversas tareas de inteligencia militar y llevar a término levantamientos cartográficos en el Magreb, en un trabajo en el que se reflejan las tensiones provocadas por la carrera imperialista en África. María Dolores González-Ripoll Navarro se ha interesado por la comunidad de cubanos emigrados a Cayo Hueso durante la segunda mitad del siglo XIX y muestra cómo los sucesivos cónsules españoles intentaron neutralizar las actividades de los independentistas por medio del empleo del espionaje y el desarrollo paralelo de una política de acercamiento. María Dolores Domingo Acebrón defendió a su vez una tesis titulada Proyección social y política de la Guerra de los Diez Años: Cuba (1868-1878), en la que, entre otros aspectos, se estudia la creación por parte de las autoridades españolas de una red de espionaje en los puntos neurálgicos donde se encontraban los rebeldes exiliados en el extranjero, llegando incluso al propio Congreso de los Estados Unidos, con el fin primordial de que la beligerancia no les fuera reconocida. Más sintéticos y con una visión más global son los breves artículos de Francisco Sánchez Ruano, Agustín R. Rodríguez González o Rafael Moreno Izquierdo, todos ellos referidos a las redes de espionaje durante la guerra de 1898. Asimismo, pueden encontrarse varias referencias interesantes relacionadas con este mismo tema en algunas de las contribuciones publicadas en las Actas del Congreso Internacional de Historia Militar celebrado en Madrid y Ávila en 1998, entre las que cabría destacar especialmente la de Milagros Flores Román y la de Graham A. Cosmas ${ }^{31}$.

${ }^{31}$ L. URTEAGA, F. NADAL y J. I. MURo, «Imperialismo y cartografía: la organización de la Comisión española de Estado Mayor en Marruecos, 1881-1882», en Scripta Nova. Revista Electrónica de Geografía y Ciencias Sociales 7 (142) (2003), 14 págs.; Mª D. GONZÁLEZ-RIPOLL NAVARRo, «La emigración cubana de Cayo Hueso (1855-1896): independencia, tabaco y revolución", en Revista de Indias 58 (212) (1998), 237-254; $\mathrm{M}^{2}$ D. DoMINGo ACEBRón, Proyeccion social y política de la Guerra de los Diez Años: Cuba (18681878), Madrid Universidad Autónoma, 1987 (tesis doctoral); F. SÁNCHEZ RUANO, «El espionaje en la guerra de 1898», en Historia 1622 (268) (1998), 62-68; A. R. RodRíGuEZGONZÁLEZ, «El espionaje español en la guerra de Cuba», en Revista Española de Defensa 127 (1998), 60-61; R. MORENo IZQUIERDO, «El servicio de inteligencia de los Estados Unidos», en Revista Española de Defensa 127 (1998), 62-63; M. FLORES RoMÁN, «Un espía llamado Whitney", en A. RUMEU dE ARMas et al. (eds.), Monografías del Ceseden 29 (1999), 271-280; G. A. Cosmas, «De La Habana a Santiago. Decisiones operacionales de Estados Unidos para Cuba, 1898», Monografías del Ceseden 29 (1999), 132-146. 
Sobre las actividades de los servicios de información y espionaje en España durante la Primera Guerra Mundial, las perspectivas de futuro son muy halagüeñas si tenemos en cuenta que en los años venideros serán publicados los resultados de un proyecto de investigación titulado «Espionaje y relaciones internacionales: los servicios de información aliados en España durante la Primera Guerra Mundial», actualmente en fase de desarrollo en el Instituto de Historia del CSIC. Este proyecto aportará datos muy novedosos y colmará en cierta medida el actual vacío historiográfico por lo que a esta temática se refiere y, en este sentido, debemos reseñar la inmediata publicación de tres contribuciones firmadas por sendos miembros del equipo de investigación de dicho proyecto en la Revista de Historia Militar. Por lo demás, apenas contamos hasta el momento con unas cuantas publicaciones, realmente escasas si tenemos en cuenta la importancia geoestratégica de la Península Ibérica a lo largo de todo el conflicto. La más interesante de ellas, aunque muy antigua, es la monografía de $\mathrm{P}$. Louis Rivière, Un centre de guerre secrète: Madrid 1914-1918. Podemos encontrar múltiples referencias a la acción de los agentes secretios alemanes y aliados en las islas Canarias en la obra que publicó Ronald Ley, Rumores de espionaje: Wolfgang Köhler y los monos en Tenerife, así como en la tesis doctoral de Francisco Javier Ponce Marrero, Canarias y la política exterior española en la Primera Guerra mundial, 1914-1918. En otro orden de cosas, debemos tener en cuenta que Barcelona se convirtió durante la Gran Guerra en uno de los principales centros del espionaje internacional $\mathrm{y}$, por este motivo, podemos encontrar algunas referencias a este tema en un trabajo de Jorge Ventura Subirats sobre la figura del Barón de König; un artículo de León Ignacio en el que se investigan las actividades del comisario Bravo Portillo; o una contribución de Antoni Rigol y Jordi Sebas tián sobre el caso Savolta. Por lo que se refiere a las actividades de información o espionaje llevadas a cabo por españoles fuera de la Península, resultan interesantes las memorias de un agente español llamado Jaime Mir, que sirvió a los aliados en Bélgica, tituladas Por qué me condenaron a muerte; un pequeño estudio de Fernando Redondo Díaz sobre los observadores militares españoles en el transcurso de la guerra, o el breve trabajo de Eduardo Manzano Moreno en el que se analizan los sucesos en Palestina a través de las informaciones extraídas de los diarios del cónsul español D. Antonio de la Cierva y Lewita, conde de Ballobar ${ }^{32}$.

32 F. García SANZ, «Información, espionaje y contraespionaje en España durante la I Guerra Mundial» en Revista de Historia Militar (monográfico sobre «Los servicios de in- 
Resulta cuando menos sorprendente el completo secano historiográfico ante el que nos hemos encontrado durante el periodo que va desde el inicio de la dictadura de Miguel Primo de Rivera hasta el estallido de la Guerra Civil, sobre todo teniendo en cuenta que por aquellos años se produjo el enfrentamiento bélico con Marruecos y que, de facto, tenemos indicios de la existencia de unas embrionarias redes de información en el norte de África. Tampoco podemos destacar ninguna referencia de interés referida al periodo correspondiente a la II República. Sin embargo, contamos con un número relativamente importante de monografías que nos informan de la situación de los servicios de información durante la contienda civil que se produjo en España entre 1936 y 1939. De hecho, podemos afirmar sin temor a equivocarnos que se trata, junto al periodo correspondiente al reinado de Felipe II, de la fase histórica mejor conocida y más tratada por la historiografía española. Sin embargo, a pesar de los avances realizados en los últimos años en el conocimiento de estas redes de espionaje, la situación actual sigue siendo deficitaria y, desde luego, habrá que seguir trabajando porque todavía quedan muchas lagunas.

En primer lugar, hemos de referirnos a aquellas obras que o bien fueron escritas por algunos de los protagonistas de las redes de espionaje

\begin{abstract}
formación modernos y contemporáneos», cit. en nota 4); E. GONZÁLEZ CALLEJA, «Los servicios de información franceses en España durante la I Guerra Mundial», ibid., y Ma D. ELIZALDE PÉREZ-GRUESO, «Los servicios de información británicos en España durante la I Gue rra Mundial", ibid; P. L. RIviÈRE, Un centre de guerre secrète: Madrid 1914-1918. La guerre politique. L'oeuvre de propagande. L'entreprise, París, Payot, 1936; R. LEY, Rumores de espionaje: Wolfgang Köhler y los monos en Tenerife, Sta. Cruz de Tenerife, J. L. García, 1995. Cf. la introducción y las notas de J. L. GARCÍA PÉREZ, así como, de este mismo autor, "Un libro en la historia del espionaje en Canarias», en F. Morales PADrón (dir.), X Coloquio de Historia canario-americana (1992), Las Palmas de Gran Canaria, Cabildo Insular de Gran Canaria, 1994, 1077-1082; F. J. PONCE MARRERo, Canarias y la política exterior española en la Primera Guerra mundial, 1914-1918: el protagonismo internacional de las islas como escenario de confrontación diplomática y estratégica, Las Palmas de Gran Canaria, Universidad de Las Palmas, 2001 (tesis doctoral); J. VenTuRA SUBIRATS, «La verdadera personalidad del «Barón de König»«, en Cuadernos de Historia Económica de Cataluña 5 (1971), 103-118; L. IGNACIO, "Bravo Portillo comisario y pistolero" en Historia y Vida 16 (181) (1983), 68-76; A. Rigol y J. Sebastián, «Cataluña y la Primera Guerra Mundial: la verdad sobre el caso Savoltan, en Film-Historia 4 (2) (1994), 153-164; J. MIR, Por qué me condenaron a muerte. (Memorias de un condenado a muerte por los alemanes, 1914-1918) (pról. de Luis Araquistain), Madrid, Editorial Fénix, 1933; F. REDondo DíAz, «Los observadores militares españoles en la Primera Guerra Mundial», en Revista de Historia Militar 59 (1985), 197-208; E. MANZANO MoRENo, «Jerusalén durante la I Guerra mundial: los diarios del cónsul españob, en Awraq. Estudios sobre el Mundo Árabe e Islámico Contemporáneo 11 (1990), 53-96.
\end{abstract}


que estuvieron en acción durante el conflicto y que, por este motivo, resultan de referencia obligada, o bien simplemente aparecieron publicadas en la inmediata posguerra. Por lo que se refiere al bando nacional, la más importante de todas es la que publicó José Bertrán y Musitu, el responsable del Servicio de Información de Fronteras del Nordeste de España (SIFNE) entre 1936 y 1937, aunque también aparecen informaciones interesantes en La quinta columna, de J. M. Carretero o Unos meses de información militar al servicio de Franco en el extranjero, de Antonio Cacho Zabalza. También cabe citar aquí la novela de Jaime Delgado (pseud. de Yago Miranda), en la que se relatan las actividades de los agentes de la Comandancia Militar del Bidasoa. Sin embargo, los artículos sobre este tema en esos años son mucho más raros, siendo únicamente reseñables unos pocos trabajos aparecidos en revistas militares, como por ejemplo los de Alonso Linaje, Santiago Mateo Marcos, J. C. o José Manuel Martínez Bande ${ }^{33}$.

Por lo que se refiere al bando republicano, la batalla propagandística se desarrolló a través de panfletos como el que publicó Carlos J. Contreras La "Quinta Columna»: Cómo luchar contra la provocación y el espionaje o la polémica obra Espionaje en España, firmada bajo seudónimo por Max Rieger. En 1938, en un Madrid asediado, Ernest Hemingway escribió una obra de teatro titulada precisamente La quinta columna y al año siguiente Marthe Richards publicó un libro de sobre sus experiencias en la guerra, Mes dernières missions sécretes: Espagne 1936-1938. Este mismo título también utilizado en una de sus obras por Manuel Uribarri, autor asimismo del libro El SIM de la República. Probablemente la obra más interesante sobre el tema sea el relato autobiográfico de un agente

33 J. BeRtRÁN y Musitu, Experiencias de los Servicios de Información del Nordeste de España (SIFNE). Una teoría, una técnica y una escuela sobre información general, Madrid, Espasa-Calpe, 1940; J. M. CARRETERo, La quinta columna, Madrid, Ed. El Caballero Audaz, 1940; A. CACHO ZABALZA, Unos meses de información militar al servicio de Franco en el extranjero, Alicante, Egasa, 1940; J. Miranda, Tallado en la sombra, Madrid, Escritores Españoles Contemporáneas, 1947; A. LINAJE, "Un asunto de espionaje (Recuerdos de la campaña)», en Ejército 8 (1940), 4 págs.; S. MATEo MARcos, «Un caso concreto de información: El servicio rojo en la batalla de Brunete», en Ejército 28 (1942), 47 55 ; J. C., "Historias de la mar. Un pequeño asunto de espionaje marítimo», en Revista General de Marina 130 (1946), 105-108; J. M. MARTÍNEZ BANDE, «Guerra de Liberación: Batalla de Brunete (julio 1937)", en Revista de Historia Militar 5 (1959), 157-197 (esp. el epígrafe «La información y la contrainformación», 169-170); y, del mismo autor, "Guerra de Liberación: Batalla de Guadalajara», en Revista de Historia Militar 19 (1965), 145-191 (esp. el epígrafe titulado "La información roja», pp. 159-160). 
del Servicio de inteligencia especial periférico (SIEP), el anarquista aragonés Ramón Rufat, que fue publicado en Francia en 1990 con el título Espions de la République: mémoires d'un agent secret pendant la guerre d'Espagne ${ }^{34}$.

Hubo que esperar hasta la muerte de Franco para que fueran publicadas obras más extensas, entre las que hemos de destacar Los servicios de espionaje en la guerra civil española (1936-1939), de Armando Paz (pseud. de Antonio Corés), La Quinta columna, de Santos Alcocer Badenas o Espionaje: (España 1936-1939) y Los dossiers secretos de la Guerra Civil, de Domingo Pastor Petit, obras todas ellas que en su día sirvieron para dar a conocer aspectos desconocidos de la guerra secreta, pero que sin embargo han sido muy criticadas por la gran mayoria de los especialistas debido a su carácter poco riguroso. Informaciones mucho más serias son las que encontramos en tres tesis doctorales publicadas a principios de los años noventa: la de Sara Núñez de Prado y Clavell, autora de Servicios de información y propaganda en la Guerra Civil española, 1936-39; la de Gema Iglesias Rodríguez, titulada La propaganda política durante la Guerra Civil española: la España republicana; y la de Marina Casanova Gómez, La diplomacia republicana y los servicios de información durante la Guerra civil española. Asimismo, podemos encontrar referencias a este tema en la obra de Javier Cervera Gil, $M a$ drid en guerra, en la que se describe la cruda realidad de las cárceles, las checas, los paseos y las sacas de presos, así como el muestrario de sospe-

34 C. J. Contreras, La "Quinta Columna": Cómo luchar contra la provocación y el espionaje... Madrid, Sector Oeste del Partido Comunista, 1937; M. RIEGER (pseud.), Espionaje en España, Barcelona, Ediciones Unidad, 1938 (se trata en realidad de una obra colectiva atribuida a Georges Soria y Arturo Perucho, dirigida, supervisada y corregida por "Stepanov», con prefacio de José Bergamín y traducida al castellano por Lucienne y Arturo Perucho); E. Hemingway, La quinta columna, Valencia, Centre Dramatic, 1992 [1938]; M. RICHARDS, Mes dernières missions sécretes: Espagne 1936 1938, París, Les Éd. de France, 1939; M. URIBarri, La Quinta Columna, La Habana, Tipografía La Universal, 1943; del mismo autor, El SIM de la República, La Habana, 1942; R. RUFAT, Espions de la République: mémoires d'un agent secret pendant la guerre d'Espagne, [París], Allia, 1990 (traducción de Entre los hijos de la noche: memorias de un agente republicano del Servicio de inteligencia especial periferico (SIEP) durante la Guerra civil española de 1936-1939, una obra escrita en 1986, merecedora del primer premio «Juan García Durán» sobre memorias de la guerra civil de la Universidad de Barcelona, y que por desgracia sigue inédita en nuestro país); del mismo autor, «Le service d'espionnage de l'Armée républicaine pendant la guerre civile espagnole de 1936-1939» en Matériaux pour l'histoire de notre temps, 3-4 (1985) (monográfico titulado «L'Espagne, 1900-1985»). 
chosos, espías y quintacolumnistas que pululaban por la capital en los años del conflicto ${ }^{35}$.

Sobre los servicios de información y las redes de espionaje españoles instalados en el extranjero durante la guerra, además de las obras publicadas en la inmediata posguerra por Bertrán y Musitu, Cacho Zabalza o Delgado, ya citadas, hemos de mencionar, mucho más recientes, entre las que sobresalen, particularmente, aquellas relacionadas con las actividades desarrolladas en territorio francés, sobre las que se han publicado dos estudios muy meritorios que por su factura constituyen dos hitos historiográficos fundamentales en la historia de los servicios de inteligencia en España. En 1996 Félix Luengo Teixidor publicó Espias en la Embajada: los servicios de información secreta republicanos en Francia durante la Guerra Civil, una obra en la que se analiza la importante actividad que llevaron a cabo los espías republicanos en territorio galo, a través de la embajada en París y de los diversos consulados, con el objetivo de contrarrestar la destacada presencia del espionaje enemigo instalado en el sur de Francia. Cinco años más tarde, Pedro Barruso Bares puso en circulación su obra El frente silencioso. La Guerra civil española en el sudoeste de Francia (1936-1940), que retoma parte de los contenidos del libro de Luengo Teixidor, pero desarrollando en profundidad la intensa lucha secreta que sostuvieron en las cercanías de la frontera vascofrancesa los servicios secretos republicanos y los agentes franquistas, quienes a su vez contaron con la colaboración de un grupo de espías alemanes e italianos. A nivel metodológico, este libro resulta impecable de-

35 A. PAZ, Los servicios de espionaje en la guerra civil española (1936-1939), Madrid, San Martín, 1976; S. Alcocer BaDENAS, La Quinta columna, Madrid, Gregorio del Toro, 1976; D. PAstor PETIT, Espionaje: (España 1936-1939), Barcelona, Bruguera, 1977; del mismo autor, Los dossiers secretos de la Guerra Civil. Barcelona, Librería Editorial Argos, 1978; La cinquena columna a Catalunya, 1936-39, Barcelona, Galba Edicions, 1978, y también «El espionaje en la guerra civil española», en Historia y Vida 23 (273) (1990), 74-83; S. NÚÑEZ DE PRADO Y ClaVELL, Servicios de información y propaganda en la guerra civil española, 1936-39, Madrid, Editorial de la Universidad Complutense, 1992 (tesis doctoral); de la misma autora, "Los servicios de información republicanos (1936-39)", en Anuario del Departamento de Historia 3 (1991), 31-43; M. CASANOVA GómEz, La diplomacia republicana y los servicios de información durante la Guerra civil española. La labor diplomática del Prof. Jiménez de Asúa, Madrid, Uned, 1993 (tesis doctoral); de la misma autora, La diplomacia española durante la Guerra civil, Madrid, Ministerio de Asuntos Exteriores, 1996; de la misma autora, «Depuración de funcionarios diplomáticos durante la guerra civil», en Espacio, Tiempo y Forma 4 (1987), 31-39; J. Cerverera GIL, Madrid en guerra: la ciudad clandestina, 1936/1939, Madrid, Alianza Editorial, 1998. 
bido al empleo de fuentes documentales inéditas procedentes de archivos españoles, franceses e italianos ${ }^{36}$.

Si las memorias, monografías y las tesis referidas a este periodo son relativamente abundantes, lo mismo cabe decir de los artículos de investigación o divulgación científica, entre los que tenemos que destacar los de Ricardo de la Cierva sobre Feliciano Martín Villoria, el coronel Ungría, la participación de Philby en la guerra o las actividades secretas desarrolladas en el Peñón de Gibraltar; de Tania Juanes sobre la quinta columna; del propio Domingo Pastor Petit sobre un caso de espionaje en Barcelona; de Heleno Saña sobre la participación del almirante Canaris, el jefe de los servicios secretos alemanes, en la guerra de España; de Jesús Bescos Torres sobre las actividades de espionaje que llevaron a cabo las monjas, la mujeres de la Sección Femenina de Falange Española o las enfermeras de la Cruz Roja Española en el transcurso de la gue rra; de Daniel Sueiro sobre las conspiraciones contra la República; de Sara Núñez de Prado y Clavell otra vez sobre las quintas columnas; de Marina Casanova sobre la implicación de los anarquistas, los servicios de inteligencia, la policía y la diplomacia en el supuesto complot contra Negrín en mayo de 1937; de José Coll i Pujol y José L. Infiesta Pérez sobre el mercante inglés «Lake Lugano»; de Willard C. Frank Jr. sobre los submarinos republicanos españoles bajo mando soviético; o de Mikel Rodríguez sobre el grupo de mujeres vascas que desarrollaron acciones de espionaje en el largo y conflictivo periodo que va de la instauración de la II República al final de la II Guerra Mundial ${ }^{37}$.

36 F. Luengo Teixidor, Espias en la Embajada: los servicios de información secreta republicanos en Francia durante la Guerra Civil, op. cit. nota 7; P. BARRUSO BARES, El frente silencioso. La Guerra civil española en el sudoeste de Francia (1936-1940), Alegia [Guipúzcoa], Hiria, 2001. Cf. también P. Zambrana Moral, C. Serrano Alcaide y J.-L. HAGUE RomA, «Solidarité, financement et espionnage dans la communauté bourgeoise catalane exilée en France mediterranéenne (Roussillon, Languedoc, Provence) pendant la Guerre civile espagnole», en Provence Historique 47 (187) (1997), 163-175; y muy especialmente la obra de Y. PECH, Les services secrets républicains espagnols en France durant la guerre civile: l'action du SIDE (1936-1939), Toulouse, Loubatières, 2005, una thèse de maîtrise merecedora del "Prix d'Histoire Militaire» que otorga anualmente el Ministère de la Défense et des Anciens Combattants del gobierno francés en la edición correspondiente al año 2002.

${ }^{37}$ R. DE LA CiERVA, «Revisión histórica del caso Philby. ¿Espía en España?» en His» toria y Vida 1(1) (1968), 86-97; del mismo autor, «La roca de los espías. Gibraltar en los años treinta», en Historia y Vida 1(2) (1968), 98-109; del mismo autor, "Feliciano Martín Villoria. El agente que justificó a la "Quinta Columna"», en Historia y Vida 1 (3) (1968), 56-65; del mismo autor, "La guerra secreta del coronel Ungría», en Historia y Vida 1(10) 
Los trabajos profesionales publicados sobre los distintos aspectos organizativos o tecnológicos referidos a los servicios de información de los ejércitos comienzan a tener cierto eco en las publicaciones militares una vez terminada la Guerra civil. De este modo, ven la luz sucesivamente obras como La información y los servicios en las Unidades de Infantería, de Narciso Ariza, en la que se abordan temas como la inteligencia, el abastecimiento, la sanidad o la organización militar; $E l$ servicio de información de la caballería, de David Azcarretazábal y Ochoa de Retana; El servicio de información operativo, de Manuel Chamorro Martínez, sin lugar a dudas uno de los grandes especialistas sobre estos temas en aquellos años; o La organización informativa y el agente secreto, Luis Canis Matutes, con prólogo del general José Ungría. Por lo que se refiere a las revistas, los primeros artículos que hemos localizado eran simples traducciones de revistas especializadas extranjeras, sobre todo americanas, pero enseguida van a comenzar a publicar sus contribuciones algunos especialistas españoles como Juan Mateo Marcos, Antonio Cores, A. Sarmiento, Manuel Chamorro, Pedro Pardo Riquelme, Antonio Lage Sanmiguel; Calixto Arroyo Merino o J. Díaz Lorda. A principios de los años cincuenta se inicia una larga travesía del desierto, que dura casi tres décadas, en donde los trabajos relacionados con los servicios de información desde el punto de vista militar desaparecen casi completamente, con la única excepción quizás de un manual publicado en 1963 por Antonio Díaz Carmona, La información y la seguridad del Estado: útil para los Suboficiales y Clases de tropa y algunos artículos muy puntuales sobre el tema, como los pu-

(1968), 4-15; T. JUANES, «La quinta columna, espías de Franco», en Tiempo de Historia 4 (46) (1978), 4-9; D. PASTOR PETTT, «Escuela de Mata-Haris. El caso del estanco de la calle de la Paja en Barcelona», en Historia 164 (38) (1979), 45-47; H. SAÑA, «El almirante Canaris. Jefe de los servicios secretos alemanes y espía en España», en Tiempo de Historia 7 (75) (1981), 64-81; J. BEscos ToRREs, "Las enfermeras en la guerra de España», en Revista de Historia Militar 26 (53) (1982), 97-143; D. SUEIRO, "Conspiración contra la República: un secreto a voces», Historia 168 (86) (1983), 11-22; S. NúÑ̈EZ DE PRADO Y ClavelL, "Las Quintas Columnas en la Guerra civil española», en Anuario del Departamento de Historia 1 (1989), 223-232; M. CASANOVA, «Información o desinformación. Un supuesto complot anarquista contra Negrín", en Espacio, Tiempo y Forma. Historia Contemporánea 9 (1996), 151-158; J. COLl I Pujol y J. L. InfIesta PÉREZ, «Las peripecias del mercante inglés «Lake Lugano» durante la Guerra civil española», en Revista de Historia Naval 53 (1996), 35-51; W. C. FRANK Jr., "Submarinos republicanos españoles bajo mando soviético (I)", en Revista de Historia Naval 64 (1999) 7-51 (esp. el epígrafe "Espionaje fascista»); M. RODRÍGUEZ, "Aventureras, espías y contrabandistas», en Historia 1625 (304) (2001), 66-73. 


\section{Los servicios de inteligencia en la historiografía española}

blicados por Castrillo Maceres, J. A. P. Castelló Ribas o F. Obrador Se$\mathrm{rra}^{38}$.

Desde luego, la bibliografía referente a la historia de las actividades de los servicios secretos en España a lo largo de la Segunda Guerra Mundial es relativamente amplia. Una vez más, debemos iniciar el epígrafe citando una obra escrita por Domingo Pastor Petit, Espionaje, la Segunda Guerra Mundial y España, si bien es cierto que sus contenidos no coinciden exactamente con lo que reza al título. También podemos encontrar muchas referencias a los servicios de espionaje instalados en España en el libro de Manuel Ros Agudo, La guerra secreta de Franco, en el de José María Irujo, La lista negra: los espias nazis protegidos por Franco y la Iglesia; o incluso en el de Patricia Martínez de Vicente, Embassy, y la inteligencia de Mambrú, en el que se relatan las actividades de Eduardo Martínez, un médico de origen gallego, apolítico y pacifista que durante la II Guerra Mundial colaboró en Madrid con el servicio se-

38 N. ARIZA, La información y los servicios en las Unidades de Infantería, Madrid, [s.n.], [1940]; D. AZCARRETAZÁBAL Y OCHOA DE RETANA, El servicio de información de la caballería, [s.l.], [s.n], 1940, 13 págs. (se trata de una conferencia del Curso de formación del Estado Mayor del Ejército); L. CANIs MATuTEs, La organización informativa y el agente secreto, Madrid, [s.n.], 1947; J. MATEO MARCos, «Servicio de Información de Artillería (S.I.A)», en Ejército 7 (1940), 5 págs; del mismo autor, con el mismo título, Ejército 15 (1941), 17-23; A. CoREs, «El servicio de Información», en Ejército 9 (1940), 8 págs; del mismo autor, "Servicio de Información del Aire», Revista de Aeronáutica y Astronáutica 10 (1941), 695-697; A. SARMIENTO, «Servicios de escucha y cifra», en Ejército 16 (1941), 7480; M. CHAMORRO, «El servicio de Información», en Ejército 20 (1941), 3-10; del mismo autor, “El servicio de información en la paz», en Ejército 36 (1943), 11-17; del mismo autor, «El Servicio de Información norteamericano», en Ejército 110 (1949), 31-38; del mismo autor, «Las segundas Secciones de los Es. Ms. Métodos de trabajo», en Ejército 115 (1949), 49-55; P. PARDO RIQUELME, "Servicio de escucha radioeléctrico", en Ejército 33 (1942), 6568; A. LAGE SANMIGUEL, «La sorpresa de comunicaciones radioeléctricas», en Ejército 39 (1943), 18-24; C. ARroyo Merino, «Baterias de localización por el sonido. Interpretación de un oscilograma", en Ejército 43 (1943), 52-57; del mismo autor "Los Grupos de Información de Artillería», en Ejército 51. (1944), 77-81; del mismo autor, "Grupos de I. A. Equipos de restitución de fotografias", en Ejército 66 (1945), 59-64; J. DÍAz LoRDA, «Aviación de información', en Revista de Aeronáutica y Astronáutica 97 (1948), 947-956; A. Díaz CARMONA, La información y la seguridad del Estado: útil para los Suboficiales y Clases de tropa, Madrid, [s.n.], 1963; CASTRILlo MAZERES, «El momento actual del Servicio de Información Operativo», en Ejército 268 (1962), 11-16; J. A. P. CASTELló RIBAs, «El valor de un conocimiento en inteligencia», en Revista General de Marina 175 (1968) 209-219 (se trata en realidad de un trabajo publicado con anterioridad en Argentina, en el Boletín del Centro Naval); F. OBRADOR SERRA, «La inteligencia como instrumento de la política», en Revista General de Marina 182 (1972), 21-29. 
creto británico y salvó a cientos de refugiados perseguidos por el III Reich. También aportan datos interesantes un pequeño artículo de $R$. Moreno Izquierdo sobre los planes aliados para invadir España, con documentación inédita, así como una contribución de Alejandro Pizarroso Quintero sobre propaganda americana en España a través del cine. Asimismo, el papel de los servicios secretos extranjeros instalados en España y su vinculación con el desarrollo de la Segunda Guerra mundial han sido objeto de algunos estudios, entre los que cabe destacar el relato autobiográfico de Mavis Bacca Dowden, Acusada d'espia a la Barcelona franquista 1939-1943 o el artículo de Carlos Collado Seidel sobre las actividades del espionaje alemán ${ }^{39}$.

La frontera pirenaica y Gibraltar se convirtieron en auténticos nidos de espías durante todo el transcurso del conflicto y, por este motivo, contamos con una bibliografía relativamente importante sobre el tema. Ferrán Sánchez Agustí ha publicado una monografía titulada Espías, contrabando, maquis y evasión. La Segunda guerra mundial en los Pirineos, en la que se aborda, entre otras cuestiones, la de las actividades de los servicios de espionaje a lo largo de la frontera franco-española. Y aunque su ámbito cronológico exceda al referido exclusivamente al periodo de la Segunda Guerra Mundial, debemos incluir en este apartado el estudio de Antonio Téllez Solá titulado La red de evasión del grupo Ponzán: anarquistas en la guerra secreta contra el franquismo y el nazismo (19361944). Por lo que se refiere Gibraltar, su importancia geoestratégica a la postre resultó crucial. Véanse si no el libro de Enrique Arques, Espías en Gibraltar; el de David Jato Miranda, Gibraltar decidió la guerra; y, especialmente, Juego de topos, un relato personal sobre el MI6 escrito por

39 D. PAstor PettT, Espionaje, la Segunda Guerra Mundial y España, Esplugues de Llobregat (Barcelona), Plaza y Janés, 1990; M. Ros AGudo, La guerra secreta de Franco, Barcelona, Crítica, 2002; de este mismo autor, Neutralidad sospechosa: España y la ayuda encubierta al Eje durante la Segunda Guerra mundial, Madrid, Universidad Complutense, 1999 (tesis doctoral); J. M ${ }^{a}$ IRUJO, La lista negra: los espias nazis protegidos por Franco y la Iglesia, Madrid, Aguilar, 2003; P. MARTínez DE VICEnTE, Embassy, y la inteligencia de Mambrú, Madrid, Velecío Editores, 2003; R. MoRENo IZQUIERDo, «Segunda Guerra mundial. Los planes aliados para invadir España", en Historia 1622 (268) (1998), 6-12; A. PIZARroso QUinTERo, «El cine americano en España durante la Segunda Guerra mundial: información y propaganda", en REDEN. Revista Española de Estudios Norteamericanos 5 (7) (1994), 121-155; M. BACCA Dowden, Acusada d'espia a la Barcelona franquista 1939-1943, Barcelona, Pòrtic, 1994; de la misma autora, «Espía en España», en Historia 1622 (256) (1997), 112-125; C. CoLIADO SEIDEL, «España y los agentes alemanes 1944-1947. Intransigencia y pragmatismo político», en Espacio, Tiempo y Forma. Historia Contemporánea 5 (1992), 431-482. 
Los servicios de inteligencia en la historiografía española

un ex-agente del servicio, Desmond Bristow, quien pasó la mayor parte de Segunda Guerra mundial en Gibraltar y en Arge $^{40}$.

Sobre las actividades de información y espionaje llevadas a cabo por españoles en el exterior, los investigadores han centrado su interés en dos de ellas: en primer lugar, la de los servicios de información vinculados al gobierno vasco en el exilio y, en segundo lugar, la de la red de espías españoles dirigida por Ángel Alcázar de Velasco al servicio de Japón. Por lo que se refiere a la primera, sobresalen la serie de contribuciones firmadas por Koldo San Sebastián, un pequeño estudio de María de los Ángeles Ordaz Romay, un artículo y la tesis doctoral de Juan Carlos Jiménez de Aberasturi Corta, en los que se pone de manifiesto hasta qué punto el posicionamiento político del presidente Aguirre propició la estrecha colaboración de los nacionalistas vascos con los servicios secretos aliados el objetivo de asegurarse su apoyo para el momento, considerado inminente, de la caída de Franco, un artículo de José Antonio de Durañona Aberasturi, de contenido similar al anterior, en el que se muestra cómo el gobierno de Euskadi en el exilio decidió movilizar a los refugiados vascos que se hallaban en territorio francés para ponerlos al servicio de los aliados, y cómo posteriormente este ofrecimiento se va a ir convirtiendo en una estrecha colaboración con sus servicios de inteligencia; así como un par de artículos de Mikel Rodríguez. Sin embargo, la obra más sobresaliente de todas las publicadas hasta el momento sobre estas cuestiones sigue siendo la de Manuel de Dios Unanue, autor de El caso Galíndez: Los vascos en los servicios de inteligencia de $E E U U$, uno de los pocos clásicos que ha generado la historiografía española. Sobre la red de espías españoles dirigida por Ángel Alcázar de Velasco al servicio de Japón existen varios trabajos entre los que cabe destacar los de Antonio Marquina Barrio, Sara Núñez de Prado y Clavell o Florentino Rodao García, autor de un libro titulado Franco y el imperio japonés, en el que además de aportar datos inéditos sobre la acción de la Falange exterior en Extremo Oriente, las tentativas de declaración de guerra a Japón por parte de Franco en 1945, se analiza en profundidad

40 F. SÁNCHez AGUSTÍ, Espias, contrabando, maquis y evasión. La Segunda guerra mundial en los Pirineos, Lleida, Milenio, 2003; A. TÉLlez Solá, La red de evasión del grupo Ponzán: anarquistas en la guerra secreta contra el franquismo y el nazismo (19361944), Barcelona, Virus, 1996; E. ARQUES, Espías en Gibraltar: (Del diario de un corresponsal de guerra), Tetuán, Editora Marroquí, 1954; D. JATo MiRANDA, Gibraltar decidió la guerra, Barcelona, Ediciones Acervo, 1978; D. BRIsTow y B. BRISTOW, Juego de topos, Barcelona, Ediciones B, 1993 [ $1^{\text {a }}$ ed. en inglés, 1993]. 
esta red de espionaje japonés en España. Para finalizar este epígrafe relativo a las redes de espionaje formadas por españoles pero con implicaciones internacionales, debemos citar un trabajo de Susana Sueiro Seoane en el que aparecen varias referencias a las actividades secretas en Marruecos ${ }^{41}$.

Hay dos operaciones secretas realizadas en el transcurso de la Segunda Guerra Mundial que han sido objeto de varias investigaciones y que están protagonizadas por personajes con cierta vinculación con nuestro país. El primer caso se hizo público cuando Nigel West (seudónimo de Rupert Allason, en realidad uno de los mayores especialistas mundiales en historia del espionaje), localizó en Venezuela a Juan Pujol, el espía español que, convertido en agente doble, consiguió engañar a los servicios de inteligencia alemanes haciéndoles creer que el desembarco de Normandía se produciría finalmente en la zona de Calais. West publicó hace años una larga entrevista con Pujol en la que se relataban sus peripecias como espía al servicio de los aliados, Garbo: el espía del siglo; luego fue publicado Garbo: doble agente, el sumario del caso elaborado por Tomás Harris, el agente británico que diseñó el engaño, y ahora acaba de apa-

41 K. SAN Sebastián, «Todavía ayer. El Servicio Vasco de Información», en Euskadi 222, 223, 224, 225 (1985-1986); $\mathrm{M}^{\mathrm{a}}$ de los Á. ORDAZ ROMAY, «El FBI y los vascos del exilio de 1939 en Estados Unidos", en R. Escobedo Mansilla, A. DE Zaballa BEAsCoeciheA y Ó. Álvarez Gila (eds.), Emigración y redes sociales de los vascos en América. VI Congreso Internacional de Historia de América (1994, Vitoria-Gasteiz), Vitoria-Gasteiz, Universidad del País Vasco, 1996, 229-240; J. C. JIMÉNez de ABERAsTuRI CorTA, «Los vascos en la II Guerra mundial: de la derrota a la esperanza», en Oihenart. Cuadernos de Lengua y Literatura 14 (1997), 57-84; del mismo autor, De la derrota a la esperanza. Políticas vascas durante la II Guerra Mundial (1937-1947), Oñate, Instituto Vasco de Administración Pública, [1999]; J. A. de DURAÑONA ABERASTURI, «Les services secrets basques pendant la 2ème guerre mondiale», en Oihenart. Cuadernos de Lengua y Literatura 14 (1997), 147 161; M. RodRíGuEZ, «Espías vascos al servicio de Estados Unidos», en Historia 1623 (276) (1999), 24-36; y, del mismo autor, «Espías vascos al servicio del FBI (1942-1947)», en Historia 1625 (300) (2001), 64-72; M. DE DIOs UNANUE, El caso Galindez: los vascos en los servicios de inteligencia de EEUU, Tafalla [Navarra], Txalaparta, [1999] [1 ${ }^{\text {a }}$ ed, Nueva York, 1982]; A. MARQUINA BARRIO, «"To", espías de verbena. USA controló la red japonesa integrada por españoles», en Historia 163 (32) (1978), 11-18; S. NúÑEZ DE PRADo Y ClAVELL, "La otra guerra del Japón (1939-1945)», en Anuario del Departamento de Historia 2 (1990), 75-83; F. RoDAo Franco y el imperio japonés, Barcelona, Plaza \& Janés, 2002; de este mismo autor, Las relaciones hispano-japonesas, 1937-1945, Madrid, Universidad Complutense, 1992 (tesis doctoral); de este mismo autor, «España, espiada por EE.UU. en la II Guerra mundial», en Historia 1620 (233) (1995), 17-24; S. SuEIRo SEOANE, «España en Tanger durante la Segunda Guerra mundial: la consumación de un viejo anhelo", en Espacio, Tiempo y Forma. Historia Contemporánea 7 (1994), 135-163. 
Los servicios de inteligencia en la historiografía española

recer en el mercado editorial español una obra con marchamo de best-seller, escrita por Javier Juárez y titulada Juan Pujol, el espía que derrotó a Hitler. El segundo episodio, referido a la famosa «Operación Carne Picada», no está protagonizado por ningún español, pero tiene la peculiaridad de que buena parte de su desarrollo se produjo en España, más concretamente en la provincia de Huelva, y por ello no resulta sorprendente que hayan sido publicadas dos monografías sobre el tema, la de Jesús Ramírez Copeiro del Villar, Huelva en la II guerra mundial: espías y neutrales y la de José María Segovia Azcárate, El enigma de William Martin: recordando el apasionante caso de espionaje que abrió las puertas de la paz a la Segunda Guerra Mundial ${ }^{42}$.

Sin lugar a dudas, la mayor laguna, y la más sorprendente también, que existe todavía en la actualidad por lo que a la historia de los servicios de inteligencia en España se refiere, es la que se dibuja al describir la producción bibliográfica referida al espionaje franquista y, más concretamente, a las dos décadas que discurren entre 1950 y 1970. La misma situación de secano productivo que caracteriza a las publicaciones militares, se da también en el mundo editorial y en el ámbito universitario. Antes de que aparezca la figura de Domingo Pastor Petit, que publica su primera obra en 1961, únicamente podemos señalar un par de contribuciones dignas de interés, la Historia del espionaje de José Luis Fernández-Rúa, y El espionaje ante la moral, de Carlos del Saz-Orozco. En el resto de los casos, o bien se trata de traducciones de libros extranjeros, o bien son obras con fines propagandísticos, como es el caso del opúsculo titulado Comunismo y masonería, firmado por Eduardo Comín Colomer y Alejandro Botzáris. Sin embargo, ningún investigador se ha interesado por estudiar los varios miles de informes elaborados en aquella época y que pasaron a engrosar los archivos policiales bajo el epígrafe «Actividades Contra el Régimen» (ACR), como muy poco es lo que sabemos todavía sobre la Organización Contrasubversiva Nacional (OCN). Únicamente podemos citar unas cuantas obras en las que aparezcan algunas referencias a este periodo, como por ejemplo es el caso de una novela titulada Cisne: espía de Franco, escrita

\footnotetext{
42 J. Pujol y N. West, Garbo: el espía del siglo, Barcelona, Planeta, 1986 [1985]; T. HARRIs; M. SEAMAN, Garbo: doble agente, Madrid, Martínez Roca, 2004 [2000]; J. JUÁREZ, Juan Pujol, el espía que derrotó a Hitler, Madrid, Temas de Hoy, 2004 J. RAMírez CoPEIRO DEL VILLAR, Huelva en la II guerra mundial: espías y neutrales, Valverde del Camino [Huelva], J. Ramírez Copeiro del Villar, 1996; J. Ma SEGOVIA AzCARÁTE, El enigma de William Martin: recordando el apasionante caso de espionaje que abrió las puertas de la paz a la Segunda Guerra Mundial, Huelva, s.n., 1998.
} 
por Luis M. González-Mata originalmente en francés al inicio de la transición política y enseguida traducida al castellano, o la monografía de Juan J. Alcalde, Los servicios secretos en España: la represión contra el movimiento libertario español (1939-1995), una obra que está centrada en el estudio de la participación de los servicios de inteligencia españoles en la persecución política de la que habría sido víctima el anarquismo tanto en la España del franquismo como en el transcurso del periodo democrático. Marcos Rodríguez Espinosa, en un artículo sobre el editor Arturo del Hoyo, hace alusiones a la controvertida presencia de servicios de inteligencia extranjeros en el mundo editorial español durante la dictadura del general Franco. Sobre la actuación y el funcionamiento de los servicios de inteligencia en el tardofranquismo contamos afortunadamente con un mayor caudal de información, aunque éste tampoco sea excesivo. Destaca especialmente el testimonio del coronel J. L. San Martín, a la sazón director del Servicio Central de Documentación (SECED), y autor de Servicio Especial. Además, sobre el asesinato de Carrero, Manuel Campo Vidal ha publicado una obra titulada Información y servicios secretos en el atentado al presidente Carrero Blanco. Evidentemente, la lucha contra ETA ha sido una de las cuestiones que han requerido más atención por parte de los servicios secretos españoles, como queda patente en el libro escrito por Manuel Cerdán y Antonio Rubio, Lobo: un topo en las entrañas de ETA o en la obra de Jorge Cabezas, Yo maté a un etarra. Secretos de un comisario de la lucha antiterrorista. Por lo que a este mismo ámbito cronológico se refiere, podemos hacer referencia al estudio de Xavier Casals sobre los vínculos entre los ultraderechistas del PENS y el SECED ${ }^{43}$.

43 J. L. FerNáNDEZ-RÚA, Historia del espionaje, Madrid, Colenda, [1953]; C. DEL SAZOROZCO, El espionaje ante la moral, Madrid, Propaganda Popular Católica; Marsiega, 1960; E. COMín COLOMER y A. BotZÁRIS, Comunismo y masonería, Segovia, [s.n] , 1951; L. M. GonzÁlez-MatA, Cisne: espía de Franco, Barcelona, Argos, 1977; J. J. AlaCALde, Los servicios secretos en España: la represión contra el movimiento libertario español (1939-1995), [Madrid], Juan J. Alcalde; Distribución, Sindicato de Oficios Varios de Madrid de la C.N.T., $1^{\text {a }}$ ed, 1995; $2^{a}$ ed., corr. y aum., 1996; M. RODRíGUEZ ESPINOSA, «Editores y traductores difusores de la historia literaria: el caso de Arturo del Hoyo en la Editorial Aguilar» en Trans. Revista de Traductología, 2 (1998), 153-163; J. L. SAN MARTín, Servicio Especial. A las órdenes de Carrero Blanco (de Castellana a El Aaiun), Barcelona, Planeta, 1983; M. CAMPo VIDAL, Información y servicios secretos en el atentado al presidente Carrero Blanco, Barcelona, Argos Vergara, 1983; M. CERDÁN y A. RUBio, Lobo: un topo en las entrañas de ETA, Barcelona, Plaza Janés, 2004; J. CABEZAS, Yo maté a un etarra. Secretos de un comisario de la lucha antiterrorista, Barcelona, Planeta, 2003; X. CASALS, «El PENS i l'extrema dreta a Catalunya, 1970-1974", en L'Avenç 147 (1991), 20-27. 
Los servicios de inteligencia en la historiografía española

\section{Historia actual de España (1978-2004) ${ }^{44}$}

Los trabajos que presentamos a continuación corresponden a aquellas investigaciones que han sido llevadas a cabo en los últimos años referidas fundamentalmente al estudio de los servicios de inteligencia en la España contemporánea. Se trata de obras realizadas desde puntos de vista muy diversos y que abordan temáticas heterogéneas, por lo que cualquier intento de sistematización, en apenas unas páginas, corre el riesgo de resultar infructuoso. Sin embargo, resulta inevitable que concluyamos nuestra guía bibliográfica con este breve epígrafe dedicado a la España actual. A nuestro juicio, la mejor obra de síntesis sobre la historia del espionaje en España, a pesar de sus notorios defectos, es la que escribieron en 2000 los periodistas Joaquín Bardavío, Pilar Cernuda y Fernando Jáuregui, publicada con el título Servicios secretos. Las tres partes en las que se divide este libro aparecen muy bien diferenciadas. En la primera, los autores abordan los antecedentes históricos de los servicios de inteligencia actuales. Se inicia el relato con la descripción de las actividades de información desarrolladas durante la Guerra de la Independencia, se recogen las andanzas de Ali Bey, Van Halen o Avinareta, y se trata la historia de estos servicios en la Guerra Civil española, en la posguerra y en el tardofranquismo. La segunda y la tercera parte abordan temas mucho más recientes, que van desde la creación del Cesid, la crisis institucional provocada por los escándalos en los que se vio envuelta la institución a mediados de los noventa hasta el final de la primera legislatura del Partido Popular. Contamos además cuando menos con una monografía dedicada a las actividades de los servicios de información y espio naje en España durante la transición. Se trata del libro escrito por el periodista Rafael Fraguas, Espías en la Transición. Secretos políticos de la España contemporánea, en el que se relatan episodios como el de la posible visita a España del dirigente soviético Lavrenti Beria en 1953, algunos aspectos poco conocidos relativos al atentado contra Carrero Blanco, llevado a cabo, según el autor, con el consentimiento de los intereses occidentales, o el temprano interés de Felipe González por acercarse al PCE. Por su parte, Miguel Platón ha publicado Hablan los militares. Testimonios para la historia (1936-1996) y más recientemente Francişco Medina ha presentado una obra de temática similar en la que abundan las

44 Sobre la importancia, posibilidades e implicaciones epistemológicas del estudio de la historia del tiempo presente en España, $c f$. J. ARósteguI, La historia vivida, Madrid, Alianza, 2004. 
referencias a nuestro tema de estudio, Memoria oculta del ejército, en la que son presentadas las confesiones de cuarenta militares que ocupan o han ocupado cargos de responsabilidad en el Ejército español, se desvelan secretos sobre el Cesid y las fuerzas armadas y se intentan aportar claves para la comprensión del papel que ha desempeñado el Ejército desde la Transición hasta hoy ${ }^{45}$.

Desde posiciones muy variadas, algunos autores han realizado interesantes contribuciones al estudio de los presupuestos teóricos de los servicios de inteligencia en la sociedad contemporánea. Uno de los principales especialistas en la historia de los servicios de inteligencia de la España actual es sin lugar a dudas el politólogo Antonio M. Díaz Fernández, autor de la única tesis doctoral realizada en nuestro país dedicada al análisis del proceso de creación y desarrollo del modelo español de inteligencia, que acaba de ser publicada bajo el título Los servicios de inteligencia españoles. Historia de una transición ${ }^{46}$.

Otros autores que han llevado a cabo estudios en este ámbito fundamentalmente teórico han sido Domingo Pastor Petit, autor de Presente y futuro del espionaje, o Fernando Pinto Cebrián, que publicó hace unos años un libro titulado La información y el arte de la guerra. Espionaje y contraespionaje militar. Debemos referirnos asimismo a los publicaciones firmadas por R. Muñoz Suay, R. Fraguas, J. Cachinero y J. Trujillo,

45 J. Bardavío, P. Cernuda y F. Jáuregui, Servicios secretos, Barcelona, Plaza \& Janés, 2000; R. FRaGuAS, Espias en la Transición. Secretos politicos de la España contemporánea, Madrid, Oberón, 2003; M. Platón, Hablan los militares. testimonios para la historia (1936-1996), Barcelona, Planeta, 2001; F. MEdina, Memoria oculta del Ejército, Madrid, Espasa-Calpe, 2004.

46 A. M. DíAz FERnÁNDEz, Los servicios de Inteligencia españoles. Historia de una transición, Madrid, Alianza Editorial, 2004. La producción de este autor es, pese a su juventud, realmente muy extensa. Ha sido Premio Defensa 2003 de Investigación Científica, y además es director de un proyecto de investigación titulado «¿Hacia una política europea de inteligencia: reto comunitario o interestatal» (Univ. de Cádiz, 2002-2005). Entre sus trabajos sobre el tema sobresalen "Spain", en S. SPHIRo (coord.), Intelligence and the Media. Londres, Frank Cass, (en prensa); «La función de los Servicios de Inteligencia» en La seguridad en el siglo XXI. Granada, Ed. Comares, 155-173; «Servicios de Inteligencia y Constitución» en Anuario de Derecho Constitucional y Parlamentario 15-16 (en prensa); "Aspectos metodológicos del uso de las fuentes orales: el caso de los Servicios de Inteligencia en España» en Historia, Antropología y Fuentes Orales (en prensa); "La transformación necesaria. Estrategias de prevención", en Politica Exterior 84 (2001), 181-187; «The Spanish Intelligence Services: An Overview», Paper for the Political Sciences Association - UK 50th Annual Conference, 10-13 April 2000, London (disponible en Internet: www.psa.ac.uk/cps/2000/Diaz\%20Antonio.pdf. Consultado el 1/12/2004). 
a un artículo de B. Gambier y C. A. Zubiaur en el que se abordan temas como el de las potestades y competencias de los servicios de inteligencia en un Estado democrático, las ayudas y subvenciones que recibe, su legitimidad desde el punto de vista del derecho constitucional, etc. o a un pequeño estudio de F. Garrido Falla en el que se tratan cuestiones relacionadas con la violencia o el terrorismo de Estado y los aspectos éticos del poder en el marco de un Estado de derecho a partir del análisis de la situación político-jurídica que se produjo en España a raíz de la polémica suscitada en torno a los denominados "papeles del Cesid» y su vinculación con el caso GAL ${ }^{47}$.

El tema de los servicios de inteligencia en la sociedad contemporánea española ha sido abordado desde diferentes puntos de vista por autores procedentes de varios campos de las llamadas ciencias humanas y sociales. En la actualidad disponemos de una profusa bibliografía relativa a las relaciones entre el mundo del Derecho y los servicios de inteligencia en España, entre cuyos títulos cabe destacar el magnífico libro de Carlos Ruiz Miguel, Servicios de inteligencia y seguridad del estado constitucional, en el que se realizan comparaciones con los modelos instituidos en Gran Bretaña, Estados Unidos y Alemania y la obra de María Concepción Pérez Villalobos, Derechos fundamentales y servicios de inteligencia, en la que son estudiados los principales servicios de inteligencia en el mundo, sus categorías constitucionales y los tipos penales implicados en su actuación, y se plantean además las lagunas que presenta la nueva legislación española relativa al CNI. Los aspectos jurídicos de la delincuencia económica y el espionaje también han sido abordados en varios estudios, entre los que sobresalen los de María del Mar Carrasco Andrino, María Teresa Fernández Sánchez o Esther Morón Lerma. Han sido publicadas algunas monografías sobre espionaje y contraespionaje industrial, como por ejemplo las de Domingo Pastor Petit, Enrique Gómez Francés, José Miguel Romaña y Jesús Villasante García y Françesc M.

\footnotetext{
47 D. PASTor Petit, Presente y futuro del espionaje, Barcelona, Clío, 1972; F. PINTO CEBRIÁN, La información y el arte de la guerra. Espionaje y contraespionaje militar, Burgos, Aldecoa, 1997; R. MuÑoz SuAY, «Rasgos del espionaje en el militante clandestino», en Los Cuadernos del Norte 5 (25) (1984), 51-55; R. FRAGUAS, «Servicios secretos y razón de Estado», en Claves de Razón Práctica 14 (1991), 64-68; J. CACHINERo y J. TRUJILlo, «La guerra silenciosa: El futuro de los servicios de inteligenciam, en Política Exterior, 7 (34) (1993), 114-125; B. GAMBIER y C. A. ZUBIAUR, «La inteligencia como actividad del Estado", en Revista de Administración Pública, 131 (1993), 529-554; F. GARRIDo FALLA, «Ética y razón de Estado: los documentos del Cesid y el caso GAL, en Anales de la Real Academia de Ciencias Morales y Políticas, 48 (73) (1996), 175-191.
} 
Coll, y también han aparecido publicados numerosos artículos tanto en revistas especializadas como en revistas de divulgación. La bibliografía sobre los aspectos técnicos del espionaje tampoco es demasiado amplia. Domingo Pastor Petit ha publicado un libro en donde se abordan de manera general estas cuestiones, titulado Las técnicas de los servicios de inteligencia. Debemos destacar asimismo otras obras en las que se hace referencia constante a los aspectos tecnológicos relacionados íntimamente con el desarrollo contemporáneo de los principales servicios de inteligencia en el mundo, como lo pone de manifiesto por ejemplo Nacho García Mostazo en su libro Libertad vigilada. El espionaje de las comunicaciones. Con una orientación mucho más práctica, Francisco Viñals Carrera y María Luz Puente Balsells son autores de un útil y prolijo manual de grafología titulado Análisis de escritos y documentos en los servicios secretos. La bibliografía en estos temas es muy amplia, pero su interés para nuestro estudio resulta sin duda más limitado ${ }^{48}$.

El Centro Superior de Información de la Defensa (CESID) ha sido objeto de varias monografías. Inaugura la serie el periodista Fernando Rueda en 1993 con una obra que se mantiene durante mucho tiempo en la lista de la publicaciones más vendidas, titulada La casa: el

48 C. RuIz Miguel, Servicios de inteligencia y seguridad del estado constitucional, op. cit.; M. C. PÉRez VILlalobos, Derechos fundamentales y servicios de inteligencia, op. cit.; $\mathrm{M}^{a}$ del M. CARRASCo ANDRINo, La protección penal del secreto de empresa, Barcelona, Cedecs, 1998; Ma T. FERNÁNDEZ SÁnCHEZ, Protección penal del secreto de empresa, Madrid, Colex, 2000; E. Morón LeRMA, El secreto de empresa: protección penal y retos que plantea ante las nuevas tecnologias, Cizur Menor [Navarra], Aranzadi, 2002; D. PASTOR PETIT, El contraespionaje industrial: estrategia y táctica, Madrid, Deusto, 1991; E. GÓMEZ FRANCÉS Contraespionaje económico, Barcelona, Seguridad y Análisis, 1998; J. M. RoMAÑa, Espionaje industrial: pasado, presente y futuro de la competencia más desleal, Bilbao, Mensajero, 1999; J. VILlasAnTE GARCía y F. M. COLL, Manual técnico de contraespionaje empresarial, [Barcelona], Nitspy, 2000. Cf. además D. PASTOR PETIT, «Seguridad empresarial contra robos, atracos, terrorismo y espionaje», en Alta Dirección 97 (1981), 71-78; Á. VIÑAS, "Espionaje económico», en Los Cuadernos del Norte 5 (25) (1984), 74-84; J. L. AGUIRRE DE RETES, «Mayor desarrollo técnico en el ámbito de la seguridad», en Dirección y Progreso 99-100 (1988), 197-198; D. PASTOR PETIT, «Apuntes para una historia del espionaje industrial», en Historia y Vida 23 (266) (1990), 4-10; I. SuAREZ-ZuloaGA GaLDIZ, «Investigación sobre competidores: evolución y práctica», en Información Comercial Española. Revista de Economía 737 (1995), 123-134; D. PASTOR PETIT, Las técnicas de los servicios de inteligencia, Barcelona, Planeta, 1977; N. GARCía MosTAZo, Libertad vigilada. El espionaje de las comunicaciones., Barcelona, etc., Ediciones B, 2003; F. ViÑals CARRERA y $\mathrm{M}^{a} \mathrm{~L}$. Puente Balselis, Análisis de escritos y documentos en los servicios secretos, Barcelona, Herder, 2003. $C f$., en todo caso, las bibliografias citadas en las monografías que hemos reseñado sobre este tema. 
Los servicios de inteligencia en la historiografía española

CESID, agentes, operaciones secretas y actividades de los espias españoles. Dado el éxito editorial que supone esta publicación, aparecen otras enseguida en la misma línea. El propio Fernando Rueda y Elena Pradas se encargan de poner sobre el tapete la cuestión del espionaje privado en España, un tema en el que al parecer sobresale el protagonismo de agentes y ex agentes del CESID: Espías. Escuchas, dossiers, montajes... El mercado negro de la información en España. $\mathrm{Al}$ mismo tiempo, aparece Las sombras del poder: los servicios secretos de Carrero a Roldán, una obra firmada por Francisco Medina, y muy poco después José Antonio Sáinz de la Peña y Antonio Marquina Barrio publican un breve informe titulado Los servicios de información en un estado democrático: las inercias del CESID. Fernando Rueda y Elena Pradas vuelven a la carga en 1997 con KA, licencia para matar: qué hacen y cómo son los espías más peligrosos del Cesid, y ese mismo año Pilar Urbano pone en circulación Yo entré en el Cesid. Fernando Rueda vuelve a publicar en 1999 un libro más sobre la institución, el cuarto, con el que cierra su serie de publicaciones sobre el tema, titulado Por qué nos da miedo el Cesid. Al mismo tiempo, Fernando J. Muniesa perpetra un particular ajuste de cuentas en Espias de madera y aparecen en el mercado editorial las memorias del más famoso espía español que había pertenecido a la Casa, Juan Alberto Perote, autor de Confesiones de Perote: Revelaciones de un espía. Por su parte, en 2001, Manuel Carballal publica Los expedientes secretos: el Cesid, el control de las creencias y los fenómenos inexplicables. Como consecuencia del vigésimo aniversario del intento fallido de golpe de Estado del 23 de febrero de 1981 son publicados un gran número de libros en los que se estudia el papel jugado por los servicios secretos españoles. De este modo, prácticamente al mismo tiempo, salen a la venta 23-F: el golpe del CESID, firmado por el periodista Jesús Palacios, en el que se defiende la teoría de que la intentona había sido urdida por los servicios de inteligencia españoles y se atribuye la responsabilidad principal a Javier Calderón y a José Luis Cortina; $23 F$, La conjura de los necios, de Pilar Cernuda, Fernando Jáuregui y Miguel Ángel Menéndez, en el que se sostiene que el Cesid habría estado al corriente de la preparación del golpe, pero no lo habría planeado ni organizado, aportando como soporte documental el llamado «informe Jáudenes»; y, 23F: Ni Miláns ni Tejero, de Juan Alberto Perote, en la que más que al Cesid como institución se atribuye la intentona a algunos de sus mandos. En 2004, Florentino Ruiz Platero y el propio Javier Calderón, señalado como instigador en varios de es- 
tos libros, publican su propia versión de los hechos acaecidos aquel día en una obra titulada Algo más que el $23-F^{49}$.

Por lo que se refiere a las revistas militares, el interés por los temas relacionados con los servicios de inteligencia ha ido in crescendo con el paso de los años, tal y como pone de manifiesto el análisis de la producción desde principios de la Transición. En 1977 la situación era todavía tan sumamente deficitaria que Ramón Bravo Nuche publica un artículo sobre el tema que lleva significativamente por título «La inteligencia, esa desconocida". Sin embargo, en 1978 aparece ya una serie de artículos sobre información en la Revista de Aeronáutica y Astronáutica, y en 1982 ve la luz en esta misma publicación el primer dossier del que tengamos noticia que se centre exclusivamente en la inteligencia desde el punto de vista militar, elaborado por José Sánchez Méndez. Al año siguiente, en la revista Ejército, Cayetano Miró Valls firma una serie de artículos sobre las relaciones entre la defensa nacional y los servicios de inteligencia. Juan Narro Romero, Fernando Bartolomé Martínez, Gonzalo Rodríguez de Austria Rosales o Ángel Liberal Fernández también reflexionaron sobre estas cuestiones en aquellos años, y la década de los ochenta concluye con la publicación de un «Documento» títulado «Inteligencia y táctica», que vio la luz en el número 592 de la revista Ejército, con contribuciones de José Faura Martín, Juan Narro Romero, Diego Otero Zulueta-Reales, Valentín Martínez Valero y Bartolomé García Cano. En 1989 la División de Inteligencia del Estado Mayor del Ejército publica un manual titulado Interrogatorio táctico, en el que se abordan temas como el de los pri-

49 F. RUEDA, La casa: el CESID, agentes, operaciones secretas y actividades de los espías españoles, Madrid, Temas de Hoy, 1993; F. RUEda y E. PRAdA, Espias. Escuchas, dossiers, montajes... El mercado negro de la información en España, Madrid, Temas de Hoy, 1995; F. MEDINA, Las sombras del poder: los servicios secretos de Carrero a Roldán, Madrid, Espasa-Calpe, 1995 (en la reedición de este libro, publicada al año siguiente, aparecía un leve pero significativo cambio de subtítulo Las sombras del poder: los secretos del CESID); J. A. SÁINZ DE LA PEÑa y A. MARquina BARRIo, «Los servicios de información en un estado democrático: las inercias del CESID», en Unisci Papers 5 (1996), 54 págs.; F. RuEdA y E. PRADAS, KA, licencia para matar: qué hacen y cómo son los espías más peligrosos del Cesid, Madrid, Temas de Hoy, 1997; P. URBano, Yo entré en el Cesid, Barcelona, Plaza \& Janés, 1997.; F. J. MuniesA, Espias de madera, Tres Cantos [Madrid], Foca, 1999; J. A. Perote, Confesiones de Perote: Revelaciones de un espía. Barcelona, RBA, 1999; M. CARBAllaL, Los expedientes secretos: el Cesid, el control de las creencias y los fenómenos inexplicables, Barcelona, Planeta, 2001; J. PALACIOS, 23-F: el golpe del CESID, Barcelona, Planeta, 2001; J. A. PERote, 23-F: Ni Milans ni Tejero, Tres Cantos [Madrid], Foca, 2001; J. Calderón y F. Rutz Platero, Algo más que el 23-F, Madrid, La Esfera de los libros, 2004. 
sioneros de guerra, los servicios de inteligencia o la fuentes de información. A principios de la década de los noventa se mantienen los niveles de interés relativo por esta temática. Debemos señalar la publicación de artículos como el de Francisco San Martín de Artiñano, José Mañoso Flores, José Antonio Saiz de la Peña, Francisco José Dacoba Cerviño, Bruno J. Fernández Garrido, o Jesús Amatriaín Méndez. En 1995 ve la luz un manual sobre La inteligencia estratégica, elaborado por Arturo Vinuesa Parral, en el que se tratan temas como el de la contrainteligencia, el espionaje, el reconocimiento del terreno o el adiestramiento táctico, y se publica además el número 1 del Boletín de Inteligencia, editado por el Estado Mayor del Ejército. Ya en 1998 aparece el segundo «Documento» que la revista Ejército dedica íntegramente a «Los servicios de inteligencia», con una presentación a cargo de Víctor Velasco Gutiérrez y las contribuciones de Andrés Montero-Gómez y Manuel Astilleros Yarto. En 2000 y 2003 debemos reseñar la publicación de sendos manuales, editados en esta ocasión por el Mando de Adiestramiento y Doctrina del Ejército de Tierra, que llevan por título Inteligencia y reconocimiento de ingenieros: orientaciones e Inteligencia: doctrina, aunque se trata de trabajos "para uso interno en las Fuerzas Armadas" y en el caso de la segunda obra su grado de clasificación exige además que su difusión sea limitada. También en 2003 el Cesid edita Adecuación de la defensa a los últimos retos, un monográfico en el que se abordan temas como el de la seguridad internacional, la defensa nacional, el papel de la OTAN y el de las Fuerzas Armadas españolas, las relaciones entre Estados Unidos y Europa, etc. Han sido publicados además una serie de artículos centrados en la temática de la inteligencia desde el punto de vista militar, como los de Pedro Belmonte Rodríguez, Carlos Suárez Martinón, José Luis de Diego Jimena, Juan J. Castellano Moscoso o Javier González Vázquez. Además se inicia una nueva etapa con la publicación de un conjunto de contribuciones en los monográficos especiales en los que se describen las estructuras, funciones y actividades de determinados cuerpos o unidades del ejército, como por ejemplo los del EUROFOR, el Eurocuerpo o la nue va estructura de la OTAN. Para finalizar, en el mes de marzo de 2004 fue publicado en la Revista de Aeronáutica y Astronáutica, veintidós años después del primero, un segundo dossier monográfico dedicado a este ámbito de estudios titulado «Los servicios de inteligencia en España», con contribuciones de José Sánchez Méndez, José Enrique Díaz Díaz, Pedro Muñoz Gil, José Jiménez Ruíz, Ramón Ichaso Hernández-Rubio y Francisco Galvache Valero. Y poco después, en junio de ese mismo año, aparecía un número especial de los Cuadernos de Estrategia bajo el título 
«Estudios sobre inteligencia: fundamentos para la seguridad internacional», coordinado por Diego Navarro Bonilla y con contribuciones de Félix Vacas Fernández, Miguel A. Esteban Navarro, Elviro Aranda Álvarez, Fernando Lista Blanco y Francisco Galvache Valero. Estas dos últimas publicaciones denotan el creciente interés que este tipo de estudios han ido adquiriendo en las publicaciones militares españolas en el transcurso de los últimos años como consecuencia de un decidido apoyo institucional a la llamada "cultura de la inteligencia» ${ }^{50}$.

50 R. Bravo Nuche, "La inteligencia, esa desconocida», en Revista General de Marina 192 (1977), 173-180; del mismo autor, "Servicios de inteligencia», en Revista General de Marina 193 (1977), 185-197 (sobre los servicios secretos norteamericanos); E. DANEO PALACIOS, "Información", en Revista de Aeronáutica y Astronáutica 448 (1978), 201206; J. SÁNCHEz MÉnDEZ, «Información», en Revista de Aeronáutica y Astronáutica 449 (1978), 275-280; del mismo autor, "Inteligencia», en Revista de Aeronáutica y Astronáutica 450 (1978), 367-374; J. SÁNCHEZ MÉNDEZ, «Inteligencia», en Revista de Aeronáutica y Astronáutica 504 (1982), 1194-1233 (este dossier consta de cinco artículos: "Historia de la inteligencia en España", 1194-1203; "Introducción a la inteligencia estratégica», 12041212; "Los servicios de inteligencia en el mundo», 1213-1220; "La inteligencia en una fuerza aérea moderna», 1221-1228; y "La inteligencia como profesión», 1229-1233); del mismo autor, "La aviación en la guerra de las Malvinas», en Revista de Aeronáutica y Astronáutica 507 (1983), 263-276; del mismo autor, «Introducción al reconocimiento aéreo», en Revista de Aeronáutica y Astronáutica 520 (1984), 305-313; del mismo autor, „El poder aéreo mañana», en Revista de Aeronáutica y Astronáutica 569 (1988), 560-575; C. MrRó VALLS, «La Defensa nacional y la Inteligencia. I: La Información en la Decisión», en Ejército 516 (1983), 29-32; del mismo autor, «La Defensa nacional y la Inteligencia. II: La Inteligencia en la Defensa Nacional», en Ejército 517 (1983), 14-16; del mismo autor, «La Defensa nacional y la Inteligencia. III: Los Servicios de Inteligencia. Niveles», en Ejército 518 (1983), 13-15; del mismo autor, «La Defensa nacional y la Inteligencia. IV: La Contrainteligencia», en Ejército 519 (1983), 19-22; del mismo autor, "¿La Defensa nacional o Seguridad nacional?», en Ejército 524 (1983), 49-53; J. NARRo ROMERo, «Una necesidad urgente: especialistas en inteligencia táctica», en Ejército 516 (1983), 65-68; del mismo autor, «iMás carros! ¡Más inteligencia!», en Ejército 524 (1983), 17-24; del mismo autor, «Las Segundas Secciones y su proceso analítico creativo», Ejército 571 (1987), 53-56; F. BARTOLOMÉ MARTÍNEZ, "Los delitos que comprometen la seguridad del Estado", en Revista Española de Derecho Militar 43 (1984), 139-171 (esp. el epígrafe titulado «Delitos de espionaje», 154-157); G. RODRÍGUEZ DE AUSTRIA ROSALES, «¿Información o inteligencia?», en Ejército 586 (1988), 14-16; Á. LIBERAL FERNÁNDEZ, "La inteligencia como recurso y servidumbre», en Revista General de Marina 214 (1988), 533-543; Monográfico «Inteligencia y táctica), en Ejército 592 (1989), 30-66 (este Documento consta de los siguientes artículos: José FAURA MARTÍN, «La inteligencia», 31; Juan NARRo ROMERo, « $55^{a}$ dimensión?», 36-41; Diego OTERo ZULETA-REALES, «El interrogatorio táctico», 42-47; Juan NARRO ROMERO, «iiAlcanzado el objetivo Intel-1!!», 49-53; Valentín MATínez VALERo, «¿Unidades de inteligencia?», 54-60 y por último Bartolomé GaRCÍA CANO: «Obtener información. ¿Dónde, cuándo y por qué?», 62-66); ESTADO MAYOR DEL EJÉRCITO, DI- 


\section{Los servicios de inteligencia en la historiografía española}

Un fruto muy reciente de este impulso es la colaboración, cada vez más frecuente, entre universitarios y profesionales de la inteligencia,

VISIÓN DE INTELIGENCIA, Interrogatorio táctico, [S.l.], [s.n.], 1989; F. SAN MARTÍN DE ARTIÑANO, "Opiniones sobre inteligencia táctica y el «Centro Común de Inteligencia» en operaciones anfibias”, en Revista General de Marina 219 (1990), 621-634; J. Mañoso FloRES, «Inteligencia de brigada independiente», en Ejército 618 (1991), 34-35; F. J. DACOBA CERVIÑo, "Unidad de inteligencia de división", en Ejército 642 (1993), 38-45; B. J. Fernández Garrido, «La Sección de Inteligencia en un Estado Mayor (I)», en Revista General de Marina 226 (1994), 141-152; J. AMATRIAÍN MÉNDEZ, «Inteligencia en las operaciones de mantenimiento de la paz», en Boletín de Información 255 (1998), 17-24; A. VINUESA PARRAL, La inteligencia estratégica. Madrid, [s.n.], 1995; ESTADO MAYOR DEL EJÉRCITO, Boletin de Inteligencia 1 (1995); Monográfico "Los servicios de inteligencia", en Ejército 686 (1998), 26-51 (que incluye las siguientes contribuciones: V. VELASCO GuTIÉRREZ, «Presentación», 26-27; A. MONTERo-GóMEZ: «Valor de inteligencia», 28-36; del mismo autor: «Los medios humanos en el ciclo de inteligencia», 37-43; del mismo autor: «Prejuicio versus inteligencia», 44-47; y por último, M. AstiLleros YARTo: «Célula nacional de inteligencia española (SPNIC) en BiH", 48-51. En ese mismo número, pero no incluido en el dossier, interesa el trabajo de J. M. LuPIANi Castellanos y Z. HERnández CALVO, "Cuando la información es la misión», pp. 15-19); MANDO DE ADIESTRAMIENTO Y DOCTRINA. EJÉRCITO DE TIERRA, Inteligencia y reconocimiento de ingenieros: orientaciones, [Madrid], Dirección de Servicios Técnicos del Ejército, 2000; Inteligencia: doctrina, [Madrid], Ministerio de Defensa, Mando de Adiestramiento y Doctrina, 2003; CENTRO SUPERIOR DE INFORMACIÓN DE LA DEFENSA, «Adecuación de la defensa a los últimos retos: conclusiones del XLIC Curso monográfico», en Monografías del CESEDEN 65 (2003), 83 págs. C. SuÁrez MARTINóN, «La inteligencia en la zona militar de Melilla», en Ejército 721 (2001), 46-49; J. L. de DIEGo JiMENA, «La asimetría de la inteligencia», en Revista General de Marina 241(2001), 365-378; J. J. CAsTELLAno MosCoso, «Arquitectura de inteligencia para una misión de apoyo a la paz», en Boletín de Información 269 (2001), 37-48; J. GONZÁLEZZ VÁZQUEZZ, «La inteligencia naval en la proyección del poder naval», en Revista General de Marina 241 (2001), 365-378; "Nuestro sistema de inteligencia», en Ejército 693 (1998) ( $\mathrm{n}^{\circ}$ extraordinario dedicado al EUROFOR), 26-32; «La sección de inteligencia», en Ejército 705 (1999) ( $\mathrm{n}^{\circ}$ extraordinario dedicado al Eurocuerpo), 67-73; «La inteligencia en la División de Reacción Rápida», en Ejér. cito 707 (1999) ( ${ }^{\circ}$ extraordinario), 49-58; «Inteligencia y Seguridad en el CG», en Ejército $718\left(\mathrm{n}^{\circ}\right.$ extraordinario consagrado a la nueva estructura de la OTAN), 33-37; Monográfico "Los servicios de inteligencia en España", en Revista de Aeronáutica y Astronáutica 731 (2004), 185-217 (que incluye las siguientes contribuciones: J. DEZCALLAR DE MAZARREDO, "Servicios de inteligencia: presentación», 186-187; J. SÁNCHEZ MÉNDEZ, «Los orígenes de los Servicios de Inteligencia», 188-195; J. E. DíAZ DíAZ, «Cuerpo General de Policía: Inteligencia», 196-199; P. MuÑoz GIL, "Servicio de Información de la Guardia Civil», 200-203; J. JiMÉNEZ RUIZ, "La Inteligencia Militar», 204-209; R. ICHASO HERNÁNDEZ-RUBIO, «El Servicio Nacional de Inteligencia: del Centro Superior de Información de la Defensa al Centro Nacional de Inteligencia», 210-214; F. GALVACHE VALERo, «Hacia una Comunidad de Inteligencia», 214-217); Monográfico «Estudios sobre inteligencia: fundamentos para la seguridad internacional», en Cuadernos de Estrategia 127 (2004), 
como ponen de manifiesto la celebración de varias actividades que han tenido lugar en los últimos años, como por ejemplo la puesta en funcionamiento, a principios del año académico 2004/2005, de un Curso de «Experto universitario en servicios de inteligencia» organizado por la UNED y el Instituto Universitario "Gutiérrez Mellado», y cuyo equipo docente reúne a varios de los mejores especialistas españoles en el tema como Diego Navarro Bonilla, Javier Jordán Enamorado, Carlos Ruiz Miguel, Antonio Díaz Fernández e Ignacio Rosales Pardo. Esta novedosa relación ya ha dado lugar a las primeras publicaciones conjuntas, como es el caso del libro editado por el propio Navarro Bonilla y Miguel A. Esteban Navarro, Gestión del conocimiento y servicios de inteligencia, en el que se recogen las contribuciones de los participantes en un Seminario sobre ese tema celebrado en la Universidad Carlos $\mathrm{III}^{51}$. Además, como ha quedado reflejado en varias ocasiones a lo largo del texto, pronto serán publicadas las Actas de las Jornadas de Historia Militar, que en noviembre de 2004 fueron consagradas a "Los servicios de información modernos y contemporáneos", con la participación de destacados especialistas como el omnipresente Diego Navarro, José Uxó Palasí, Andrés Cassinello Pérez, José Ramón Urquijo Goitia, Manuel Espadas Burgos, Fernando García Sanz, Eduardo González Calleja o María Dolores Elizalde Pérez-Grueso.

191 págs. (con aportaciones de: D. NAVARRO BonILLA, «Introducción», 7-31; F. VACAS FERNÁNDEZ, "Coyuntura internacional en la que actúan los servicios de inteligencia», 3258; M. Á. EsTEBAN NAVARRo, «Necesidad, funcionamiento y misión de un servicio de inte ligencia para la seguridad y la defensa", 59-87; E. ARANDA ÁLVAREZ, "Servicios de inteligencia: un estudio comparado», 88-119; F. LISTA BLANCO, "Cooperación europea en materia de inteligencia», 120-139; y F. GALVACHE VALERO, «La inteligencia compartida», 140-168).

51 D. Navarro Bonilla y M. A. Esteban Navarro (eds.), Gestión del conocimiento y servicios de inteligencia. Madrid, Boletín Oficial del Estado y Universidad Carlos III, 2004: J. A. MoReIro GonZÁlez, "Conflictos bélicos e información: nuevas perspectivas para nuevos escenarios, 13-34; M. Á. Esteban NAVARRo y D. NAVARRo Bonilla, «Inteligencia para la seguridad y la defensa: el valor de la gestión del conocimienton, 35-54; D. NAVARRO BONILLA, «Fuentes abiertas de información e inteligencia estratégica, 55-74; J TRAMULLAS SAZ, «Tecnologías para la gestión del conocimiento y la generación de inteligencia», 75-100; J. M. MoLinA LóPEz, «Sistemas de apoyo a la decisión como herramientas de información en el ámbito militar», 101-142; A. RIBAGORDA GARNACHO, «La protección de la información en la sociedad del conocimiento: la criptografía digital», 143-154; E. ARANDA ÁLVAREZ «El marco constitucional de los servicios de inteligencia», 155-180; A. DE Asts RoIG, "Centro Nacional de Inteligencia y orden constitucional», 181-206; F. DAVARA RODRíGUEZ, «La observación espacial en la gestión de crisis», 207-218; A. VILLALBA FERNÁNDEZ, "La función de la inteligencia para la seguridad y defensa de los estados: la lucha contra el terrorismo ( la inteligencia después de la intervención en Irak)», 219-232. 
La publicación del presente monográfico de la revista Arbor, fruto de la colaboración entre el CNI y el CSIC, es una demostración más de esta nueva coyuntura.

\section{CONCLUSIONES}

Por lo que parece, un número nada despreciable de lectores potenciales se siente muy atraído por las teorías conspiratorias y, por este motivo, algunos periodistas y ciertos editores están dispuestos a poner en el mercado este tipo de producto. En el caso que nos ocupa, la historiografía de los servicios de inteligencia, ya no sólo españoles, sino de cualquier país del mundo, el terreno está estupendamente abonado, teniendo en cuenta la enorme cantidad de actividades ilícitas que estos han venido cometiendo a lo largo de la historia. Desde luego, y quizás por el interés que ha despertado la literatura y el cine de espionaje, se ha desarrollado un mercado editorial que se dedica a sacar a la luz esta literatura. La pregunta es: ¿Todo vale, a la hora de publicar la historia de las actividades de los servicios de inteligencia en España? Creemos que no y, en este sentido, viene como anillo al dedo la interesante contraposición realizada por Justo Serna entre un famoso apólogo de George Duby y una moraleja de Clifford Geertz:

«Cuenta Georges Duby en su "Diálogo sobre la historia. Conversaciones con Guy Lardreau" (Madrid, Alianza, 1988) que en cierta ocasión comenzó a leer lo que sin duda parecía el libro de un colega. Era, añade Duby, un volumen elaborado según todos los requerimientos académicos: una obra con fuentes, con bibliografía, con notas a pie de página, un texto en el que el autor se expresaba en tercera persona cancelándose, con esa forma de enunciación neutra y transparente que hacen suya los historiadores. Cuando concluyó el volumen descubrió para su sorpresa y desazón que aquel libro era una ficción urdida con los recursos de la Academia, una estafa que sólo se descubría al final, un guiño posmoderno, una exhibición metadiscursiva, como aquellas que idearon Borges o Nabokov, por ejemplo. ¿Qué lecciones extraía Duby (...)? Pues que el crédito del historiador (o del periodista, añadiríamos) en parte se debe a una serie de convenciones, convenciones que no impiden la mentira, que no son suficientes para evitar la impostura. La fe que depositamos en un investigador no se debe sólo a la confianza que suscite su persona, sino sobre todo al efecto de realidad que provoca su adhesión al esquema perceptivo imperante. Si esto es así, entonces podemos mentir largamente y con refinamiento sin que se aprecie de entrada el embuste. (..) La segunda lección que Duby extraía 
era admitir la débil línea que separa la invención de la realidad, la imaginación (o incluso la fantasía) de la verdad documentada. ¿Qué hacer, pues? Decía Clifford Geertz a este propósito que la verdad es un ideal regulativo en las ciencias sociales (o en la historia o en el periodismo). Imaginemos, añadía, a un médico de campaña que debiera intervenir quirúrgicamente. Apresurado, próximo a las bombas que caen y que amenazan con destruirlo todo, no puede exigir las mejores condiciones, esas que son habituales en tiempos de paz, las que le permiten operar en un quirófano esterilizado. Como no puede intervenir en un ambiente neutro, ¿deberíamos concluir que le da lo mismo dónde lo haga, en una sala aseada o en un estercolero? Hemos de suponer que evitará el lodazal o el muladar; hemos de suponer que tratará de tenerlo todo lo más aseadito posible, aunque sólo sea por convencer al paciente de sus buenas intenciones, aunque sólo sea para intentar salvar su vidaw ${ }^{52}$.

Poco importa si es un periodista o un historiador el que encare la tarea de llevar a cabo la historia de los servicios de inteligencia en España. Cambiarán los métodos, pero lo que nunca debe de perder de vista ninguno de los dos es el carácter riguroso de la empresa.

¿Cuál es el balance final? Desde nuestro punto de vista, hay varios indicios que justifican un moderado optimismo de cara al futuro. Por una parte, como acabamos de ver, se ha producido en los últimos años un salto cuantitativo muy importante. Aunque nuestros conocimientos sobre la historia de los servicios de inteligencia en España sean aún limitados, también es cierto que la situación ha mejorado notablemente respecto a cualquier época anterior de la historia de España. Los resultados de 2004 resultan muy alentadores, si tenemos en cuenta que a lo largo del año vieron la luz un buen número de libros sobre el tema, fueron publicados varios dossiers monográficos y se celebraron varios seminarios y cursos de verano. En la actualidad existen varios proyectos de investigación, individuales o colectivos, que están empezando a dar sus frutos precisamente ahora, $y$, sin duda, la cosecha irá progresando en los años venideros.

Desde nuestro punto de vista, sin embargo, una legislación menos ambigua que la que tenemos actualmente constituiría en el fondo una garantía para la investigación histórica, puesto que estamos convencidos de que en la medida en que los gobiernos y los servicios de inteligencia del Estado se sientan lo suficientemente protegidos, la tentación de la des-

52 Recogido en "Diarios. Blog de Arcadi Espada», http://www.arcadi.espasa.com/ 000051.html. Consultado el 1/12/ 2004. 
Los servicios de inteligencia en la historiografía española

trucción o de la apropiación indebida de aquellos documentos que pudieran ponerlos en algún tipo de compromiso será, sin duda, menor. De ahí que, ahora mismo, lo más importante para el buen desarrollo metodoló gico de esta historiografía española referida a los servicios de inteligencia es que se establezcan de verdad nuevos mecanismos de desclasificación, para que ésta sea más ágil, para que se venzan de una vez por todas las morosas inercias burocráticas y para que sea posible acceder a los documentos cuyo contenido sea ya divulgable sin necesidad de apurar los plazos máximos legales. En España, como en Brasil en 1986, como en Alemania en 1989 o como en Rusia en 1991, también se produjo un vuelco histórico que nos condujo a la instauración de un sistema político de carácter democrático del que actualmente disfruta la sociedad española. Es hora ya de saber en donde están y qué papeles contienen los archivos de los servicios secretos españoles que estuvieron en activo hasta la instauración de la democracia en este país.

En este sentido, consideramos que la historia en general, a pesar de las sucesivas crisis de identidad que ha venido sufriendo en los últimos treinta años, aún tiene una opción que ofrecer. Podemos escribir y enseñar historia no desde la perspectiva ideológico-política, según la cual el saber histórico debe servir como genealogía de los valores del presente, sino desde una perspectiva crítica. En ella la historia es el saber de lo re lativo, y no sólo porque toda la realidad histórica sea contingente, sino también porque el conocimiento de otras culturas y el conocimiento del pasado sirven para mostrarnos el carácter absolutamente contingente de nuestros valores. La historia ya no será así un discurso de reafirmación, que se asocia estrechamente al intento de imposición de esos mismos valores sobre los demás pueblos y sobre todo en el caso de la historia europea, sino que sabrá apreciar otros valores, y enseñaremos a respetarlos, a aprender de ellos y a confrontar los nuestros y los otros con los únicos que nos pueden servir de referencia: los valores éticos ideales. La capacidad relativizadora de la historia es, pues, algo que se debería valorar enormemente. El trabajo de investigación y enseñanza de la historia puede así cumplir un papel moral de importancia fundamental para la sociedad del momento presente. De ahí que afirmemos, categóricamente además, que la historia debe seguir investigándose y enseñándose a pesar de todo ${ }^{53}$.

Afortunadamente, en la tarea dialógica, moralmente responsable y políticamente comprometida en la que la historia se juega su razón de

53 Cf. J. C. Bermejo Barrera, Pensa-la Historia. Ensaios de historia teórica, Vigo, Ir Indo, 2000, 271-284. 
ser, contamos con un trecho ya andado, a pesar de las amplias zonas de sombra que presenta el trayecto. Los que vamos reconociendo como «derechos humanos universales» nos aportan el horizonte de ese punto de vista moral que necesitamos y la concreción jurídica suficiente para hacerlos cada vez más eficaces en el plano político. La historia hace bien si toma en serio la emergente cultura de los derechos humanos, continuando la batalla contra los prejuicios occidentalistas, que lastran ideológicamente las políticas de derechos humanos que se deben acometer, y radicalizando esa cultura que es fuente de salud democrática y plataforma de confluencia universalista en cuanto a pretensiones de vida digna para todos.

Resta ahora la tarea de traducir en fórmulas operativas esta historia democrática, plural, abierta y ética que nos proponemos, historia que, lo confesamos, resulta a todas luces menos fácil de realizar que de proclamar. Nosotros, los historiadores, pretendemos simplemente estudiar la historia de España en las mejores condiciones que nos sea posible. Los servicios de inteligencia, los de la Transición, los del franquismo, los de la II República, los de la dictadura de Primo de Rivera, los del largo periodo de la Restauración, e via dicendo, ya forman parte de nuestra historia $y$, sin embargo, sabemos todavía muy poco sobre cómo funcionaron, cuál era su estructura, qué servicios prestaron, etc. Abramos los archivos, localicemos los documentos, estudiémoslos, y, si es posible, ofrezcámosle a los ciudadanos más claves para la comprensión del pasado de nuestro país. Y, de paso, sentemos también las bases para que los historiadores del futuro puedan estudiar la historia de nuestros actuales servicios de inteligencia armados con mejores presupuestos teóricos y metodológicos de los que disponemos en la actualidad. Ello redundará, sin lugar a dudas, en el conocimiento más objetivo de unas organizaciones que trabajan al servicio del Estado, en aras de la seguridad de sus ciudadanos y que constituyen en sí mismas unas extraordinarias plataformas para estudiar la historia de España. 